\title{
Steady-state performance evaluation and energy assessment of a complete membrane-based liquid desiccant dehumidification system
}

\author{
Hongyu Bai ${ }^{1}$, Jie Zhu ${ }^{1, *}$, Xiangjie Chen ${ }^{1}$, Junze $\mathrm{Chu}^{1}$, Yuanlong Cui ${ }^{2}$, Yuying Yan $^{1}$ \\ ${ }^{1}$ Department of Architecture and Built Environment, the University of Nottingham, University \\ Park, Nottingham, NG7 2RD, United Kingdom \\ ${ }^{2}$ Department of Mechanical Engineering and the Built Environment, the University of Derby, \\ Derby, DE22 3AW, United Kingdom
}

\begin{abstract}
A complete membrane-based liquid desiccant dehumidification system is investigated under the steady operating condition, which mainly consists of a dehumidifier, a regenerator, three heat exchangers, a cold and a hot water supply units. A finite difference mathematical model is developed for the complete system to investigate the system dehumidification performance and energy requirement, and validated by experimental data. The dehumidification performance is evaluated by the system sensible and latent effectiveness and moisture flux rate, while its energy performance is assessed by the total cooling capacity and coefficient of performance. It is found that the number of heat transfer units in the dehumidifier side and solution to air mass flow rate ratio have the most considerable impact on the system performance, while the number of heat transfer units in the regenerator side and solution inlet concentration in the dehumidifier have comparatively weak influences. The system sensible and latent effectiveness can be improved by increasing the dehumidifier side number of heat transfer units before reaching its critical value of 6 . However, the amount of moisture being absorbed, total cooling capacity and coefficient of performance decrease with the dehumidifier side number of heat transfer units at the low air flow rate. The critical value of solution to air mass flow rate ratio varies with number of heat transfer units, and it is preferable to keep the flow rate ratio at or below its critical value as further increasing solution flow rate would reduce the system coefficient of performance.
\end{abstract}

Keywords: complete dehumidification system, liquid desiccant, numerical modelling, cooling capacity, $\mathrm{COP}$

*Corresponding author: jie.zhu@nottingham.ac.uk(J.Zhu). 


\section{Introduction}

\subsection{Research background}

Buildings account for a large portion of global energy consumption and related $\mathrm{CO}_{2}$ emission [1] , for example, they represent around 39\% and 40\% of energy consumption and 38\% and 36\% of $\mathrm{CO}_{2}$ emission in the US [2] and Europe [3] respectively. Within the building section, humidity control is of vital importance for ensuring indoor thermal comfort [4] and product quality [5]. As a matter of fact, 20-40\% of energy consumption in heating, ventilation and airconditioning (HVAC) systems is used for air dehumidification [6]. The conventional vapour compression technology which uses cooling coil to dehumidify moist air has several problems. For instance, it has relatively weak ability of dealing with latent heat load, which leads to low coefficient of performance (COP) in humid area. It also has the problems of growths of mould and bacteria, surface corrosion [7]. Thus the current trend is to make HVAC system more energy efficient and less dependent on electrical power from fossil fuels [8].

In recent years desiccant systems have been developed, which work in a different way to dew point system. Desiccant can be either solid or liquid. Compared with solid desiccant system, liquid desiccant dehumidification technology has gained great attention recently for good ability of removing latent heat load and low air pressure drop $[9,10]$. Humid air and liquid desiccant are contacted directly in the traditional system such as packed-bed columns [11]. However small droplets of liquid desiccant may be carried over to the conditioned space, which is harmful to both the building and occupants [12]. As the alternative, semi-permeable membranes are used to separate liquid desiccant and air flows to avoid the carry-over problem [13].

Extensive studies have been carried out for the membrane-based liquid desiccant dehumidification system. Bai et al. $[14,15]$ experimentally and numerically studied the coupled heat and mass transfer of a full-scale flat-plate membrane-based dehumidifier, and found that $N T U$ and mass flow rate ratio $\left(\mathrm{m}^{*}\right)$ are the key parameters influencing the dehumidifier performance, and their effects are interacted with each other. Su et al. [16] proposed a solarpowered absorption chiller combined with a liquid desiccant dehumidifier for space cooling and fresh water production, and their results reveals that the exergy efficiency for the proposed system is $2.97 \%$ higher than the reference system. Huang et al. $[17,18]$ studied the conjugate heat and mass transfer in a membrane parallel-plate contractor, and analysed the effects of local and mean friction factors, Nusselt number and Sherwood number. Apart from the dehumidifier in the dehumidification system, the regenerator is another crucial component since the diluted solution needs to be re-concentrated in the regenerator. Qi et al. [19] investigated the performance of an electrolytic dehumidifier with a polymer electrolytic membrane (PEM) element and found that the relative humidity can be decreased to less than $30 \%$ under a $3 \mathrm{~V}$ 
electric field. Lin et al. [20] conducted a thermodynamic analysis of a cross-flow membrane liquid desiccant dehumidifier, and found that the supply air at the temperature of $18.3^{\circ} \mathrm{C}$ and humidity ratio of $10.9 \mathrm{~g} / \mathrm{kg}$ under nominal conditions can be provided by combining the dehumidifier with a dew point evaporative cooler. Babu et al. [21, 22] designed and fabricated a novel proton exchange membrane (PEM) fuel cell and investigated the influences of different operating parameters on the cell performance. They found that the cell temperature has the most significant effect on the PEM fuel cell.

All studies introduced above focus on one single contractor either dehumidifier or regenerator. Mahmud et al.[23, 24] tested the steady-state performance of a run-around membrane energy exchanger (RAMEE) system, which consists of two counter-cross-flow membrane energy exchangers, one located in the supply air side and another in the exhaust air side. They found that the maximum system total effectiveness is between $50 \%$ and 55\%. Ge et al.[25] proposed an analytical model for the RAMEE, and achieved good agreements among analytical, numerical and experimental results. Seyed-Ahmadi et al. [26, 27] extended the steady-state model of the RAMEE to the transient one and found that the storage volume ratio and solution concentration have considerable influences on the transient response of the system. Moreover, Rasouli et al. [28] conducted an energetic, economic and environmental study for a health-care HVAC system equipped with the RAMEE using TRNSYS and MATLAB programs, and discovered that the RAMEE could reduce greenhouse gas emissions by up to $25 \%$ and $10 \%$ in cold and hot climates respectively.

Nevertheless, in the previous REMEE studies, the supply and exhaust exchanger is coupled with aqueous salt solution flowing in a closed loop, and it is assumed that heat and mass transfer rates in the supply exchanger are equal to those in the exhaust exchanger, in other words, there is no heat or moisture added or removed from the system. However, the system might benefit significantly from the external heat and cold sources, in which case a hot and a cold water loops are included in the configuration. The heat and mass transfer rates in the dehumidifier and regenerator may not be equal. Thus in this paper a complete membrane-based liquid desiccant dehumidification system that include a dehumidifier, a regenerator, and a hot and a cold water supply units, is investigated. A numerical model for the complete system is developed and validated by experimental results. The effects of parameters that are controllable in reality including dimensionless parameters (i.e. dehumidifier and regenerator NTUS and $m^{*}$ ) and solution inlet properties (i.e. solution concentration in the dehumidifier $C_{\text {sol,in }}$ ), on the system performance are clarified. Energy analysis is conducted through the COP and total cooling energy capacity $Q_{\text {cooling }}$. A numerical model for the complete membrane-based liquid desiccant dehumidification system containing both dehumidifier and regenerator is developed in this study for the first time, and a comprehensive parametric analysis for the complete system 
is conducted which presents valuable data for HVAC engineers to design and operate such a system in reality.

\subsection{Paper structure}

This paper mainly consists of seven sections, and one appendix. Section 1 gives the brief introduction to the research topic by providing the research background and identifying the current research gap; Section 2 presents the development and the solving method for the mathematical model built for numerical modelling; Section 3 introduces several important indices used for system performance evaluation; Section 4 explains the detailed experimental method; Section 5 validates the mathematical model by comparing the numerical results with the experimental data; Section 6 presents main results and discusses the effects of various operating parameters on the system performance; Section 7 gives major conclusions and recommendation for future research.

\section{Numerical modelling}

The developed numerical model mainly includes three sub-models: dehumidifier, regenerator and heat exchangers. The structures of the dehumidifier and regenerator are similar, only their heat and mass transfer directions are converse, therefore their models are introduced in one subsection. The following assumptions are adopted in order to address the main issues in the numerical model:

1) All components are well-insulated, including the dehumidifier, regenerator, heat exchangers, pipes and ducts, there is no heat and mass transfer between the component and the ambient environment.

2) The directions of heat and mass transfer through membrane are normal to the membrane plane.

3) Both the liquid desiccant solution and air flows in the dehumidifier and regenerator are considered as the laminar flow owing to their low Reynolds numbers $(R e)$ in most cases [29].

4) Condensation or evaporative heat is released to, or taken from the solution channels only since mass transfer coefficient in the solution side is much higher than that in the air side.

5) The physical properties of the solution and air, and their convective heat transfer coefficients are assumed to be constant at the steady operating condition.

6) Both the solution and air flows in the dehumidifier and regenerator are fully-developed type, while their temperature and humidity ratio (or concentration) vary along the channel length.

\subsection{Dehumidifier and regenerator}

The structure of the dehumidifier or regenerator, and the unit cell applied for the numerical modelling for these two heat and mass exchangers are given in Fig. 1. The air and liquid 
desiccant solution flow in cross flow arrangement through the channels formed by the alternating semi-permeable membranes. Only heat and moisture can be transferred through the membranes, the liquid desiccant is prevented from passing through them. The top and bottom of the air channels, and left and right of the solution channels are sealed so as to avoid direct contact between the air and liquid desiccant. For the dehumidifier, hot and humid air from outdoor flows along the $\mathrm{x}$-axis direction, while strong and cold solution inversely flows along the $y$-axis direction. For the regenerator, return air from conditioned space flows along the $x$ axis direction, while weak and hot solution flows along the y-axis direction.

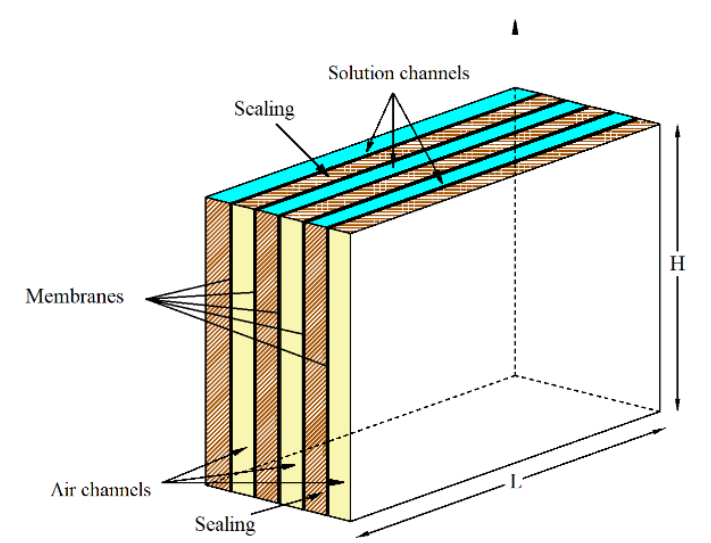

(a)

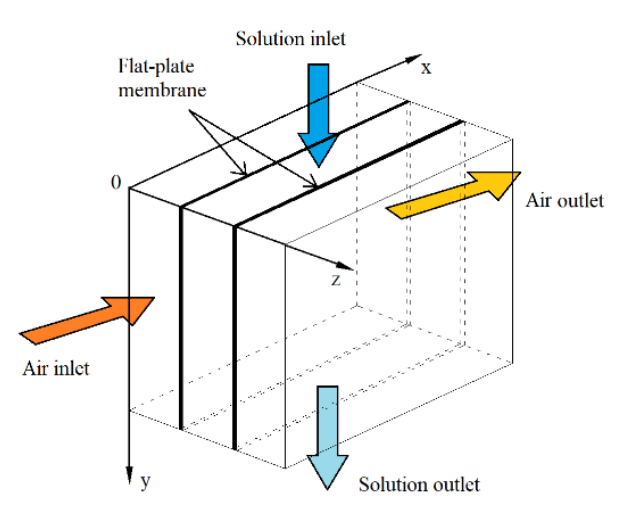

(b)

Fig. 1. Schematic structure of dehumidifier or regenerator (a); unit cell for numerical modelling (b)

\subsubsection{Governing equations}

The normalized governing equations of heat and mass conservations for the dehumidifier and regenerator are presented as:

Dehumidifier solution side:

$\frac{\partial T_{\text {sol }}{ }^{*}}{\partial y^{*}}-N T U_{m} h^{*} \frac{1}{\Upsilon^{*}}\left(W_{\text {air }}{ }^{*}-W_{\text {sol,mem }}{ }^{*}\right)-N T U \frac{1}{\Upsilon^{*}}\left(T_{\text {air }}{ }^{*}-T_{\text {sol }}{ }^{*}\right)=0$

$\frac{\partial X_{\text {sol }}}{\partial y^{*}}-N T U_{m} \frac{1}{m^{*}} W_{0}\left(1+\omega_{\text {sol }}\right)\left(W_{\text {air }}{ }^{*}-W_{\text {sol,mem }}{ }^{*}\right)=0$

Dehumidifier air side:

$\frac{\partial T_{a i r}{ }^{*}}{\partial x^{*}}+\operatorname{NTU}\left(T_{\text {air }}{ }^{*}-T_{\text {sol }}{ }^{*}\right)=0$

$\frac{\partial W_{\text {air }}{ }^{*}}{\partial x^{*}}+N T U_{m}\left(W_{\text {air }}{ }^{*}-W_{\text {sol,mem }}{ }^{*}\right)=0$

Regenerator solution side:

$\frac{\partial T_{\text {sol }}^{*}}{\partial y^{*}}+N T U_{m} h^{*} \frac{1}{\Upsilon^{*}}\left(W_{\text {sol,mem }}^{*}-W_{\text {air }}^{*}\right)+N T U \frac{1}{\Upsilon^{*}}\left(T_{\text {sol }}^{*}-T_{\text {air }}^{*}\right)=0$

$\frac{\partial X_{\text {sol }}}{\partial y^{*}}+N T U_{m} \frac{1}{m^{*}} W_{0}\left(1+\omega_{\text {sol }}\right)\left(W_{\text {sol,mem }}^{*}-W_{\text {air }}^{*}\right)=0$

Regenerator air side: 
$\frac{\partial T_{\text {air }}^{*}}{\partial x^{*}}-N T U\left(T_{\text {sol }}^{*}-T_{\text {air }}^{*}\right)=0$

$\frac{\partial W_{\text {air }}^{*}}{\partial x^{*}}-N T U_{m}\left(W_{\text {sol,mem }}^{*}-W_{\text {air }}^{*}\right)=0$

In Eqs.(2) and (6), $\omega_{s o l}$ is the inverse of solution dilution ratio and defined as:

$\omega_{\text {sol }}=\frac{\dot{m}_{\text {water }}}{\dot{m}_{\text {desi }}}=\frac{1-C_{\text {sol }}}{C_{\text {sol }}}$

where $\dot{m}_{\text {water }}$ and $\dot{m}_{\text {desi }}$ are mass flow rates of water and desiccant respectively; $C_{s o l}$ is solution mass concentration as given by:

$C_{\text {sol }}=\frac{\dot{m}_{\text {desi }}}{\dot{m}_{\text {sol }}}$

where $\dot{m}_{\text {sol }}$ is desiccant solution mass flow rate (.

A number of dimensionless parameters are defined and used to normalize the governing equations:

Dimensionless length $x^{*}$ and height $y^{*}$ :

$x^{*}=\frac{x}{L}$

$y^{*}=\frac{y}{H}$

where $L$ and $H$ are length and height of the dehumidifier or regenerator respectively as indicated in Fig. 1(a).

Dimensionless temperature $T^{*}$ and humidity ratio $W^{*}$ :

$T^{*}=\frac{T-T_{\text {air }, \text { in }}}{T_{\text {sol, in }}-T_{\text {air }, \text { in }}}$

$W^{*}=\frac{W-W_{\text {air }, \text { in }}}{W_{\text {sol,in }}-W_{\text {air, in }}}$

where $T_{\text {air, in }}$ is air temperature, $W_{\text {air,in }}$ is humidity ratio at inlets of the dehumidifier or regenerator. $T_{\text {sol,in }}$ and $W_{\text {sol,in }}$ are solution temperature and equilibrium humidity ratio at inlet of the dehumidifier or regenerator.

$m^{*}$ is mass flow rate ratio and $\Upsilon^{*}$ is thermal capacity ratio:

$m^{*}=\frac{\dot{m}_{\text {sol }}}{\dot{m}_{\text {air }}}$

$\Upsilon^{*}=\frac{\left(\dot{m} c_{p}\right)_{s o l}}{\left(\dot{m} c_{p}\right)_{a i r}}$

where $\dot{m}_{s o l}$ is solution mass flow rate, $\dot{m}_{\text {air }}$ is air mass flow rate, $c_{p, s o l}$ is solution specific heat capacity at constant pressure, $c_{p, \text { air }}$ is air specific heat capacity at constant pressure.

Dimensionless operating factor $h^{*}$ :

$h^{*}=\frac{W_{\text {sol,in }}-W_{\text {air }, \text { in }}}{T_{\text {sol,in }}-T_{\text {air, in }}} \frac{h_{f g}}{c_{p, \text { air }}}$

where $h_{f g}$ is phase change heat of water during condensation in the dehumidifier or evaporation in the regenerator respectively. 
Dimensionless parameters $N T U$ and $N T U_{m}$ are numbers of heat transfer and mass transfer units respectively, they are given by:

$$
\begin{aligned}
& N T U=\frac{U A}{\left(\dot{m} c_{p}\right)_{\text {air }}} \\
& N T U_{m}=\frac{U_{m} A}{\dot{m}_{\text {air }}}
\end{aligned}
$$

where $A$ is total membrane area. $U$ and $U_{m}$ are heat and mass transfer coefficients for the dehumidifier or regenerator respectively:

$U=\left(\frac{1}{h_{\text {air }}}+\frac{\delta}{k_{\text {mem }}}+\frac{1}{h_{\text {sol }}}\right)^{-1}$

$U_{m}=\left(\frac{1}{h_{m, a i r}}+\frac{\delta}{k_{m, m e m}}\right)^{-1}$

where $h_{\text {air }}$ and $h_{\text {sol }}$ are convection heat transfer coefficients in the air and solution sides respectively, $h_{m \text {,air }}$ is mass transfer coefficient in the air side, $k_{m e m}$ and $k_{m, m e m}$ are membrane heat and mass transfer conductivities respectively, and $\delta$ is the thickness of membrane.

\subsubsection{Boundary conditions}

The boundary conditions of temperature and humidity ratio (or concentration) in the dehumidifier and regenerator are:

Solution side:

$T_{\text {sol }}{ }^{*}=1$, at $y^{*}=0$

$X_{\text {sol }}=X_{\text {sol,in }}$, at $y^{*}=0$

Air side:

$T_{\text {air }}{ }^{*}=0$, at $x^{*}=0$

$W_{\text {air }}{ }^{*}=0$, at $x^{*}=0$

Boundary conditions of heat and moisture conservation on the membrane surface are:

$N T U_{\text {sol }}\left(T_{\text {sol,mem }}{ }^{*}-T_{\text {sol }}{ }^{*}\right)=\operatorname{NTU}\left(T_{\text {air }}{ }^{*}-T_{\text {sol,mem }}{ }^{*}\right)+N T U_{m} h^{*}\left(W_{\text {air }}{ }^{*}-W_{\text {sol,mem }}{ }^{*}\right)$

$N T U_{m} W_{\text {sol,in }}-W_{\text {air }, \text { in }}\left(W_{\text {air }}{ }^{*}-W_{\text {sol,mem }}{ }^{*}\right)=N T U_{m . s o l}\left(C_{\text {sol }}-C_{\text {sol,mem }}\right)$

where $C_{s o l, m e m}$ is solution concentration on the membrane surface; $N T U_{s o l}$ and $N T U_{m . s o l}$ are numbers of heat transfer units and mass transfer units in the solution side respectively:

$N T U_{\text {sol }}=\frac{h_{s o l} A}{\left(\dot{m} c_{p}\right)_{\text {air }}}$

$N T U_{m . s o l}=\frac{h_{m, s o l} A}{\dot{m}_{\text {air }}}$

where $h_{m, s o l}$ is mass transfer coefficient in the solution side.

\subsection{Heat exchangers}

Three liquid-to-liquid plate heat exchangers are installed in the system. The schematic diagram of the system is given in Fig. 2. The concentrated (strong) solution is cooled by cold water in 
heat exchanger 3 (HX3) before flowing into the dehumidifier. The diluted (weak) solution is heated by hot water in heat exchanger 2 (HX2) before flowing into the regenerator. Moreover, heat exchanger 1 (HX1) is used for heat recovery between the strong and weak solutions. For a heat exchanger, the effectiveness $\varepsilon$ is defined as the ratio of the actual heat transfer rate over the maximum possible heat transfer rate [30]:

$\varepsilon \equiv \frac{q}{q_{\max }}=\frac{C_{h}\left(T_{h, i}-T_{h, o}\right)}{C_{\min }\left(T_{h, i}-T_{c, i}\right)}=\frac{C_{c}\left(T_{c, o}-T_{c, i}\right)}{C_{\min }\left(T_{h, i}-T_{c, i}\right)}$

where $C_{h}$ and $C_{c}$ are heat capacity rates of hot and cold fluids respectively, $T_{h, i}, T_{h, o}, T_{c, i}$ and $T_{c, o}$ are temperatures of hot and cold fluids at inlets and outlets respectively. For the heat exchangers, their effectiveness can be defined as:

$\varepsilon_{1}=\frac{\dot{m}_{s o l} c_{p, \text { sol }}\left(T_{\text {sol,out }, r e}-T_{\text {sol }, 1}\right)}{\dot{m}_{\text {sol }} c_{p, \text { sol }}\left(T_{\text {sol, out }, r e}-T_{\text {sol }, \text { out }, \text { de }}\right)}=\frac{\dot{m}_{\text {sol }} c_{p, \text { sol }}\left(T_{\text {sol }, 2}-T_{\text {sol }, o u t, d e}\right)}{\dot{m}_{\text {sol }} c_{p, \text { sol }}\left(T_{\text {sol }, \text { out }, r e}-T_{\text {sol,out }, \text { de }}\right)}$

$\varepsilon_{2}=\frac{\dot{m}_{s o l} c_{p, s o l}\left(T_{s o l, 1}-T_{\text {sol,out }, \text { de }}\right)}{\min \left(\dot{m}_{s o l} c_{p, s o l}, \dot{m}_{\text {cooling,w }} c_{p, w}\right)\left(T_{\text {sol, } 1}-T_{\text {cooling,w,in }}\right)}$

$\varepsilon_{3}=\frac{\dot{m}_{\text {sol }} c_{p, s o l}\left(T_{s o l, i n, r e}-T_{\text {sol }, 2}\right)}{\min \left(\dot{m}_{s o l} c_{p, s o l}, \dot{m}_{h o t, w} c_{p, w}\right)\left(T_{h o t, w, i n}-T_{s o l, 2}\right)}$

where subscripts " $d e$ " and " $r e$ " denote dehumidifier and regenerator respectively. $T_{\text {cooling,w,in }}$ and $T_{h o t, w, i n}$ are inlet temperatures of cold water and hot water respectively, $T_{s o l, 1}$ and $T_{s o l, 2}$ are outlet temperatures of strong and weak solutions in HX1, as shown in Fig. 2. $\dot{m}_{\text {cooling,w }}$ and $\dot{m}_{h o t, w}$ are mass flow rates of cold and hot water respectively.

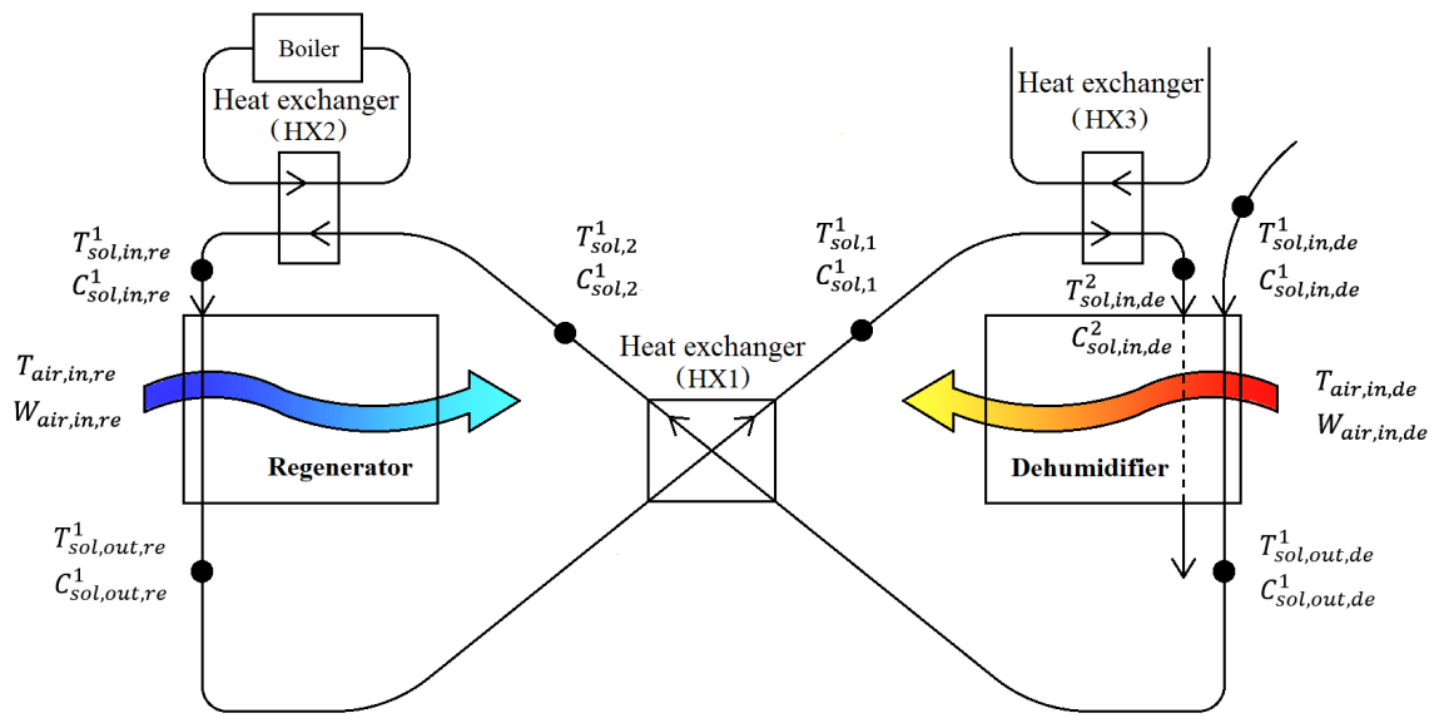

Fig. 2. Schematic diagram of the complete dehumidification system

\subsection{Simulation procedure}

The finite difference method is used to solve the above governing equations. Eqs. (1)-(8) are discretized by forward difference scheme. They are presented in Appendix A.

The discretised governing equations for the air and solution flows are solved in Matlab iteratively until the required convergence has been achieved. The flow chart of numerical 
solving scheme is indicated in Fig. 3. It is found that the result difference between $30 \times 60$ grids and $50 \times 100$ grids is less than $1.0 \%$, which means $30 \times 60$ grids are sufficient for the modelling in this study. The numerical uncertainty is less than $1.0 \%$.

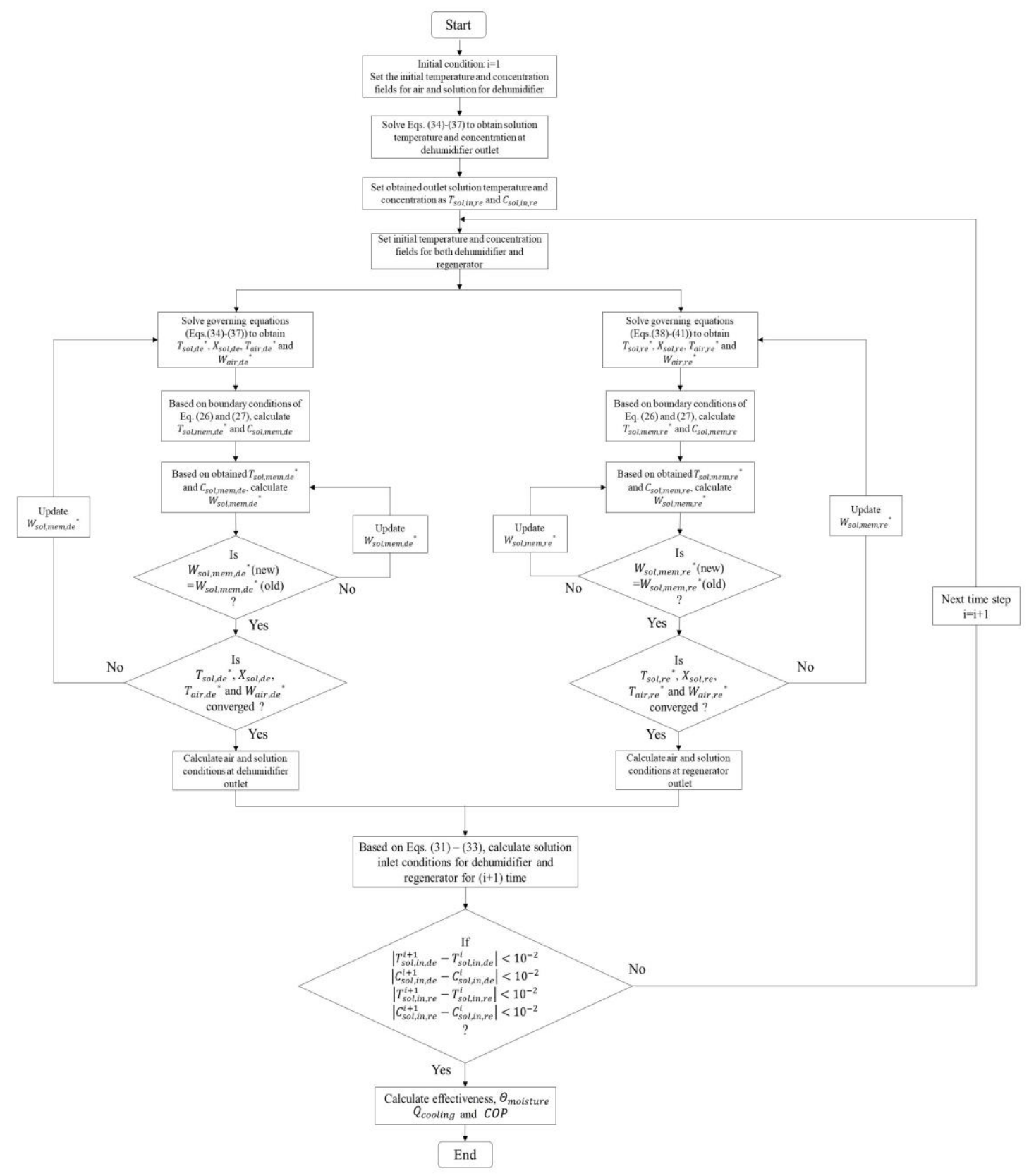

Fig. 3. Flow chart of the numerical solving scheme

\section{System performance indices}

\subsection{System effectiveness}

Effectiveness are the important dimensionless parameters used for the performance evaluation of heat and mass exchanger. Effectiveness for the dehumidifier and regenerator have been defined separately and illustrated in previous studies [14, 15, 31]. For the complete system, the 
overall system sensible effectiveness $\varepsilon_{s e n, s y s}$ is defined as the ratio of actual sensible heat transfer rate between two fluids over the maximum possible sensible heat transfer rate in the system, the overall system latent effectiveness $\varepsilon_{\text {lat,sys }}$ is defined as the ratio of actual latent heat transfer rate between two fluids over the maximum possible latent heat transfer rate in the system. They can be expressed as follows when $\Upsilon^{*}>1$ :

$\varepsilon_{\text {sen,sys }}=\frac{\left(\dot{m} c_{p}\right)_{a i r, d e}\left(T_{a i r, i n, d e}-T_{a i r, o u t, d e}\right)}{\min \left(\left(\dot{m} c_{p}\right)_{a i r, d e^{\prime}}\left(\dot{m} c_{p}\right)_{s o l}\right)\left(T_{a i r, i n, d e}-T_{s o l, i n, d e}\right)}$
$\varepsilon_{\text {lat }, s y s}=\frac{\dot{m}_{a i r, d e} h_{f g}\left(W_{a i r, i n, d e}-W_{\text {air }, \text { out }, d e}\right)}{\min \left(\dot{m}_{\text {air }, d e} h_{f g}, \dot{m}_{\text {sol }} h_{f g}\right)\left(W_{\text {air }, i n, d e}-W_{\text {sol, in }, d e}\right)}$

\subsection{Moisture flux rate $\Theta_{\text {moisture }}$}

Moisture removal rate $\dot{m}_{\text {moisture }}$ is an index of the quantity of moisture being absorbed by desiccant solution in the dehumidifier, and given by:

$\dot{m}_{\text {moisture }}=\dot{m}_{\text {air }, \text { de }}\left(W_{\text {air }, \text { in }, \text { de }}-W_{\text {air,out }, \text { de }}\right)$

Then moisture flux rate $\Theta_{\text {moisture }}$ is defined as a dimensionless parameter that represents the ratio of moisture removal rate $\dot{m}_{\text {moisture }}$ to the membrane overall mass transfer conductance. Compared to $\dot{m}_{\text {moisture }}$, the moisture flux rate is only dependent on the inlet state and not related to the dehumidifier's geometric properties. $\Theta_{\text {moisture }}$ can be calculated by:

$\Theta_{\text {moisture }}=\frac{\dot{m}_{\text {moisture }}}{U_{m} A}=\frac{\dot{m}_{\text {air }, \text { de }}\left(W_{\text {air }, \text { in }, d e}-W_{\text {air }, \text { out }, d e}\right)}{U_{m} A}$

\subsection{Total cooling capacity $Q_{\text {cooling }}$}

The most critical function of the dehumidification system is to reduce moisture content in the moist air (latent cooling load), and its temperature as well (sensible cooling load). Therefore the total cooling capacity $Q_{\text {cooling }}$ should be assessed, which is the sum of the system sensible and latent cooling capacities:

$Q_{\text {cooling }}=Q_{\text {sen }}+Q_{\text {lat }}$

where $Q_{\text {sen }}$ and $Q_{\text {lat }}$ are system sensible and latent cooling capacities respectively, and defined as:

$Q_{\text {sen }}=\dot{m}_{\text {air }, d e} C_{p, a i r}\left(T_{a i r, i n, d e}-T_{a i r, o u t, d e}\right)$

$Q_{\text {lat }}=\dot{m}_{\text {moisture }} \times h_{f g}=\dot{m}_{\text {air }, d e} h_{f g}\left(W_{\text {air,in,de }}-W_{\text {air,out }, \text { de }}\right)$

\subsection{Coefficient of performance COP}

To evaluate energy efficiency of the system, coefficient of performance $C O P$ is defined as:

COP $=\frac{Q_{\text {cooling }}}{Q_{\text {reg }}+W_{\text {fan }}+W_{\text {pump }}}=\frac{Q_{\text {sen }}+Q_{\text {lat }}}{Q_{\text {reg }}+W_{\text {fan }}+W_{\text {pump }}}$

where $Q_{\text {reg }}$ is regeneration heat input, which is given by:

$Q_{\text {reg }}=\dot{m}_{\text {sol }} c_{p, \text { sol }}\left(T_{\text {sol,in,re }}-T_{\text {sol,out,re }}\right)$ 
where $W_{\text {pump }}$ is pump power consumption; $W_{\text {fan }}$ is fan power consumption, which can be gotten by:

$W_{\text {fan }}=\frac{W_{\text {output }}}{\eta_{\text {fan }}}=\frac{Q_{\text {fan }} \Delta P}{\eta_{\text {fan }}}=\frac{\dot{m}_{\text {air }} \Delta P}{\rho_{\text {air }} \eta_{\text {fan }}}$

where $W_{\text {output }}$ is fan power output, in other words it is the useful power output applied to the air; $\eta_{f a n}$ is fan efficiency; $Q_{f a n}$ is fan air volumetric flow rate; $\Delta P$ is air pressure drop in the dehumidifier or regenerator, which can be obtained by:

$\Delta P=\frac{1}{2} \rho_{\text {air }} u_{\text {air }}{ }^{2}\left(\frac{A_{d e, r e}}{A_{d}}\right)^{2}\left(\frac{A_{d}}{A_{d e, r e}}-1\right)^{2}$

where $u_{\text {air }}$ is air velocity; $A_{d e, r e}$ is windward area of the dehumidifier or regenerator; $A_{d}$ is cross area of the duct connected to the dehumidifier or regenerator.

\section{Experiment set up}

A test rig for the complete membrane-based liquid desiccant dehumidification system is built in the laboratory of The University of Nottingham, and shown in Fig. 4.

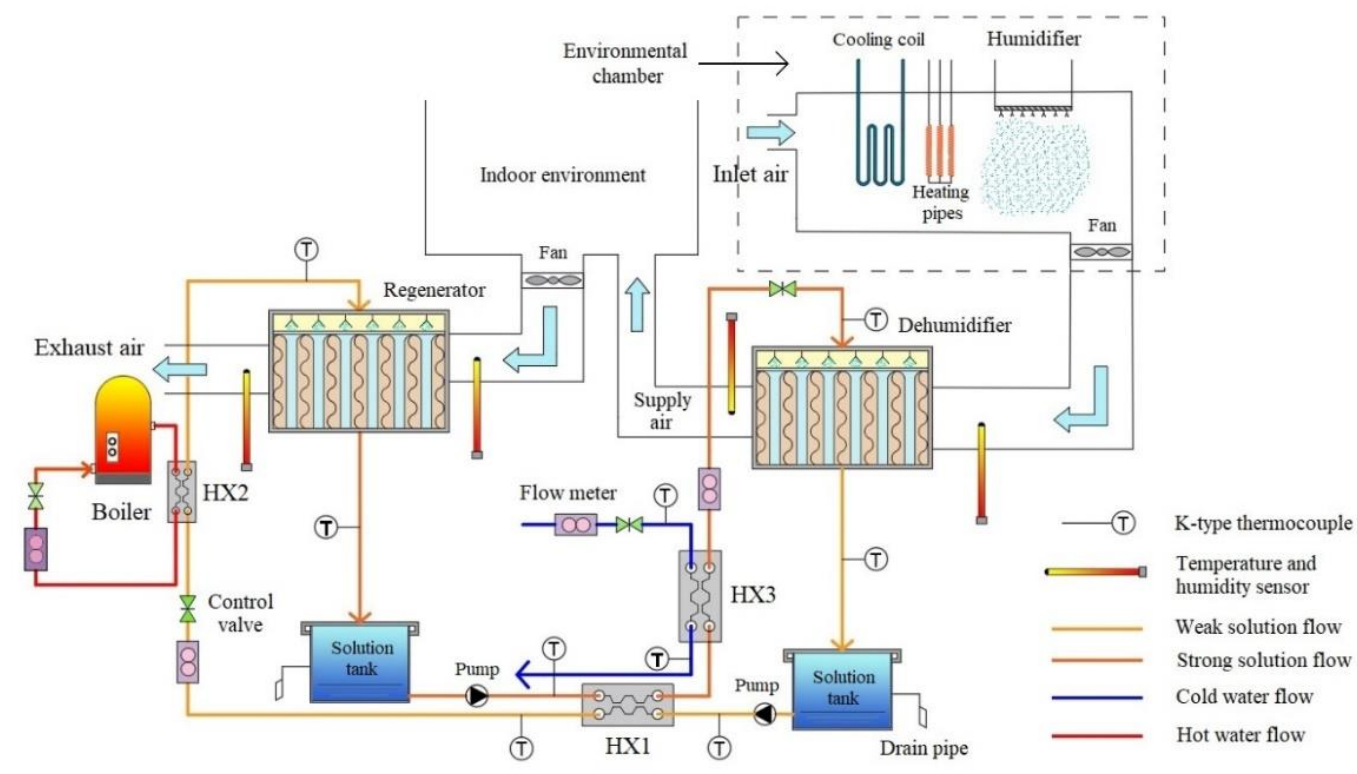

Fig. 4. Test rig of the complete liquid desiccant dehumidification system

As indicated in Fig. 4, the complete system consists of one air dehumidifier, one solution regenerator, two solution tanks, three liquid-to-liquid heat exchangers, one hot water and one cold water supply units. Lithium chloride $(\mathrm{LiCl})$ solution is selected as the working liquid desiccant. Strong solution is cooled by cold water before flowing into the dehumidifier, the supply air temperature and humidity ratio are reduced by the strong solution in the dehumidifier, at the same time the strong solution is diluted. The exhaust air from the indoor environment is used as the regeneration air in the regenerator, where the air is humidified and heated, and then discharged to the outside eventually. A solution heat exchanger (HX1) is used between the diluted and re-concentrated solutions for heat recovery, the diluted solution is further heated by 
hot water before flowing into the regenerator. Two solution tanks are used to collect the solutions. With regards to experimental set-up, the air flow rates are controlled by two variable speed fans and measured by Testo thermos-anemometer with measurement range of $0-10 \mathrm{~m} / \mathrm{s}$ and accuracy of $\pm 5 \%$. The solution circulation is realized by two $15 \mathrm{~W}$ centrifugal magnetically driven pumps, and its flow rates through the dehumidifier and regenerator are adjusted by two liquid flow indicators with measurement range of $1-15 \mathrm{~L} / \mathrm{min}$ and accuracy of $\pm 5 \%$. The solution concentration is obtained based on its density using Brannan hydrometer with accuracy of $\pm 2 \%$. The hot water is provided by a boiler with temperature range of $20^{\circ} \mathrm{C}$ to $80^{\circ} \mathrm{C}$, and the cold water is from the main supply pipe with temperature of $14^{\circ} \mathrm{C}$. Temperatures of the solution and water are measured by K-type thermocouples with measurement range of $0-1100^{\circ} \mathrm{C}$ and accuracy of $\pm 0.75 \%$. Humidity of air is obtained by Sensiron Evaluation KIT with measurement range of $0-100 \%$ and accuracy of $\pm 3 \%$. All sensors are connected to a DT500 data logger with accuracy of $\pm 0.15 \%$ for data acquisition. Schematic diagram of the membrane-based units is given in Fig. 5. Physical and transport properties of the dehumidifier and regenerator are displayed in Table 1.

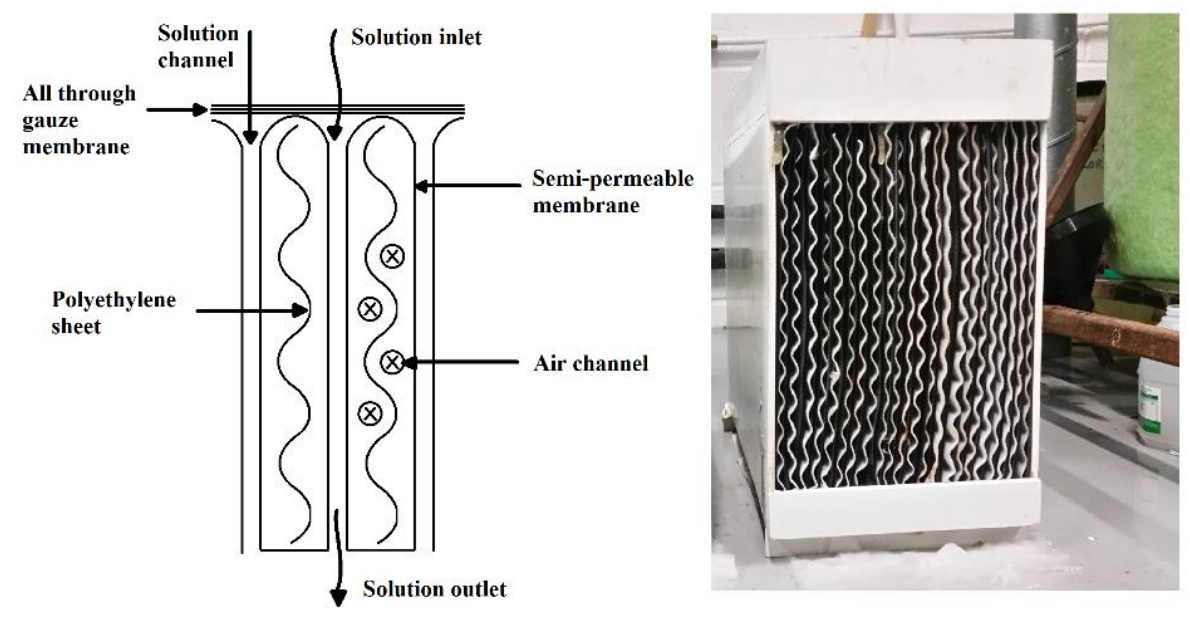

Fig. 5. Schematic diagram of membrane-based units 


\section{Table 1}

Physical and transport properties of dehumidifier and regenerator

\begin{tabular}{|l|l|l|l|}
\hline Description & Notation & Unit & Value \\
\hline Length of dehumidifier (regenerator) & L & $m$ & 0.41 \\
\hline Width of dehumidifier (regenerator) & $W$ & $m$ & 0.186 \\
\hline Height of dehumidifier (regenerator) & $H$ & $m$ & 0.23 \\
\hline Air channel thickness & $d_{\text {air }}$ & $m$ & 0.0077 \\
\hline Solution channel thickness & $d_{\text {sol }}$ & $m$ & 0.0043 \\
\hline Membrane thickness & $\delta_{\text {mem }}$ & $m$ & $0.5 \times 10^{-3}$ \\
\hline Membrane conductivity & $k_{\text {mem }}$ & $\mathrm{kW/mK}$ & $3 \times 10^{-4}$ \\
\hline Membrane mass transfer conductivity & $k_{m, m e m}$ & $\mathrm{~kg} / \mathrm{ms}$ & $3.87 \times 10^{-6}$ \\
\hline Air specific heat capacity & $c_{p, \text { air }}$ & $\mathrm{J} / \mathrm{kgK}$ & 1020 \\
\hline Solution specific heat capacity & $c_{p, \text { sol }}$ & $\mathrm{J} / \mathrm{kgK}$ & 3200 \\
\hline Air side diffusivity & $D_{\text {air }}$ & $\mathrm{m}^{2} / \mathrm{s}$ & $2.46 \times 10^{-5}$ \\
\hline Solution side diffusivity & $D_{\text {sol }}$ & $\mathrm{m}^{2} / \mathrm{s}$ & $0.892 \times 10^{-2}$ \\
\hline Air side heat conductivity & $k_{\text {air }}$ & $\mathrm{W} / \mathrm{Mk}$ & 0.03 \\
\hline Solution side heat conductivity & $k_{\text {sol }}$ & $\mathrm{W} / \mathrm{Mk}$ & 0.53 \\
\hline Air side Nusselt number & $\mathrm{Nuair}$ & - & 6.58 \\
\hline Solution side Nusselt number & $\mathrm{Nu}$ sol & - & 7.74 \\
\hline Air side Sherwood number & $S h_{\text {air }}$ & - & 6.7 \\
\hline
\end{tabular}

\section{Numerical model validation}

The numerical model of the complete system is validated by experimental data. 30 groups of experimental tests under various operating conditions have been carried out. Both the hot water and cold water flow rates are set as $0.006 \mathrm{~kg} / \mathrm{s}$, and their temperatures are set as $60^{\circ} \mathrm{C}$ and $14^{\circ} \mathrm{C}$ respectively. The regenerator air inlet temperature $T_{\text {air, in,re }}$ and humidity ratio $W_{\text {air, in,re }}$ are set as $28^{\circ} \mathrm{C}$ and $0.012 \mathrm{~kg} / \mathrm{kg}$ respectively. The effects of the dehumidifier side $N T U$ number $N T U_{d e}$, regenerator side $N T U$ number $N T U_{r e}$, mass flow rate ratio $m^{*}$, and dehumidifier inlet solution concentration $C_{\text {sol,in,de }}$ are assessed. The system sensible effectiveness $\varepsilon_{\text {sen,sys }}$, latent effectiveness $\varepsilon_{\text {lat,sys }}$ and moisture flux rate $\Theta_{\text {moisture }}$ are adopted to compare the numerical and experimental results. The comparison results are given in Table 2, it is found that the maximum relative errors are $13.29 \%, 12.72 \%$ and $12.96 \%$ for $\varepsilon_{\text {sen,sys }}, \varepsilon_{\text {lat,sys }}$ and $\Theta_{\text {moisture }}$. Generally speaking, the variation trends of numerical and experimental results are similar, a good agreement between them has been reached. This means the numerical model can be used to predict the performance of the complete membrane-based liquid desiccant dehumidification system. 
Table 2

Calculated and tested performance indices under different operating conditions

\begin{tabular}{|c|c|c|c|c|c|c|c|c|c|c|}
\hline \multicolumn{8}{|c|}{ Operating conditions } & \multicolumn{3}{|c|}{ Comparisons } \\
\hline $\mathrm{NTU}_{\text {de }}$ & $\mathrm{NTU}_{\mathrm{re}}$ & $\begin{array}{c}\mathrm{m}_{\text {sol }} \\
(\mathrm{kg} / \mathrm{s})\end{array}$ & $\mathrm{m}^{*}$ & $\begin{array}{c}\mathrm{T}_{\text {sol,in,de }} \\
\left({ }^{\circ} \mathrm{C}\right)\end{array}$ & $\begin{array}{c}\mathrm{C}_{\mathrm{sol}, \text { in,de }} \\
(\%)\end{array}$ & $\begin{array}{c}\mathrm{T}_{\text {air,in,de }} \\
\left({ }^{\circ} \mathrm{C}\right)\end{array}$ & $\begin{array}{c}\mathrm{W}_{\text {air,in,de }} \\
(\mathrm{kg} / \mathrm{kg})\end{array}$ & $\varepsilon_{\text {sen,num }}$ & $\varepsilon_{\text {sen,exp }}$ & $\begin{array}{c}\text { Error } \\
(\%)\end{array}$ \\
\hline 1 & 4 & 0.009 & - & 25 & 39 & 28 & 0.012 & 0.3184 & 0.281 & 11.746 \\
\hline 4 & 4 & 0.009 & - & 25 & 39 & 28 & 0.012 & 0.7817 & 0.749 & 4.183 \\
\hline 8 & 4 & 0.009 & - & 25 & 39 & 28 & 0.012 & 0.9379 & 0.883 & 5.854 \\
\hline 1 & 4 & 0.012 & - & 25 & 39 & 28 & 0.012 & 0.2769 & 0.251 & 9.354 \\
\hline 4 & 4 & 0.012 & - & 25 & 39 & 28 & 0.012 & 0.6991 & 0.667 & 4.592 \\
\hline 8 & 4 & 0.012 & - & 25 & 39 & 28 & 0.012 & 0.8525 & 0.798 & 6.393 \\
\hline 4 & 1 & 0.009 & - & 25 & 39 & 28 & 0.012 & 0.8014 & 0.764 & 4.667 \\
\hline 4 & 4 & 0.009 & - & 25 & 39 & 28 & 0.012 & 0.7817 & 0.759 & 2.904 \\
\hline 4 & 8 & 0.009 & - & 25 & 39 & 28 & 0.012 & 0.7711 & 0.732 & 5.071 \\
\hline 4 & 1 & 0.012 & - & 25 & 39 & 28 & 0.012 & 0.7442 & 0.718 & 3.521 \\
\hline 4 & 4 & 0.012 & - & 25 & 39 & 28 & 0.012 & 0.6991 & 0.667 & 4.592 \\
\hline 4 & 8 & 0.012 & - & 25 & 39 & 28 & 0.012 & 0.6778 & 0.637 & 6.020 \\
\hline 4 & 4 & 0.0056 & 1 & 25 & 39 & 28 & 0.012 & 0.7244 & 0.688 & 5.025 \\
\hline 4 & 4 & 0.0112 & 2 & 25 & 39 & 28 & 0.012 & 0.7309 & 0.768 & -5.076 \\
\hline 4 & 4 & 0.0224 & 4 & 25 & 39 & 28 & 0.012 & 0.3356 & 0.291 & 13.290 \\
\hline 6 & 6 & 0.0037 & 1 & 25 & 39 & 28 & 0.012 & 0.7659 & 0.724 & 5.470 \\
\hline 6 & 6 & 0.0074 & 2 & 25 & 39 & 28 & 0.012 & 0.9063 & 0.870 & 4.005 \\
\hline 6 & 6 & 0.0148 & 4 & 25 & 39 & 28 & 0.012 & 0.6678 & 0.629 & 5.810 \\
\hline 4 & 4 & 0.0056 & 1 & 25 & 30 & 28 & 0.012 & 0.8263 & 0.811 & 1.852 \\
\hline 4 & 4 & 0.0056 & 1 & 25 & 36 & 28 & 0.012 & 0.7898 & 0.769 & 3.743 \\
\hline 4 & 4 & 0.0056 & 1 & 25 & 42 & 28 & 0.012 & 0.7732 & 0.738 & 4.553 \\
\hline 4 & 4 & 0.0056 & 1 & 25 & 39 & 28 & 0.01 & 0.8449 & 0.862 & -2.024 \\
\hline 4 & 4 & 0.0056 & 1 & 25 & 39 & 30 & 0.01 & 0.8674 & 0.819 & 5.580 \\
\hline 4 & 4 & 0.0056 & 1 & 25 & 39 & 34 & 0.01 & 0.8897 & 0.913 & -2.619 \\
\hline 4 & 4 & 0.0056 & 1 & 25 & 39 & 28 & 0.015 & 0.7505 & 0.718 & 4.330 \\
\hline 4 & 4 & 0.0056 & 1 & 25 & 39 & 30 & 0.015 & 0.7856 & 0.739 & 5.932 \\
\hline 4 & 4 & 0.0056 & 1 & 25 & 39 & 34 & 0.015 & 0.8254 & 0.791 & 4.168 \\
\hline 4 & 4 & 0.0056 & 1 & 25 & 39 & 28 & 0.02 & 0.6462 & 0.598 & 7.459 \\
\hline 4 & 4 & 0.0056 & 1 & 25 & 39 & 30 & 0.02 & 0.6968 & 0.712 & -2.181 \\
\hline 4 & 4 & 0.0056 & 1 & 25 & 39 & 34 & 0.02 & 0.757 & 0.704 & 7.001 \\
\hline \multicolumn{8}{|c|}{ Operating conditions } & \multicolumn{3}{|c|}{ Comparisons } \\
\hline $\mathrm{NTU}_{\mathrm{de}}$ & $\mathrm{NTU}_{\text {re }}$ & $\begin{array}{c}\mathrm{m}_{\text {sol }} \\
(\mathrm{kg} / \mathrm{s})\end{array}$ & $\mathrm{m}^{*}$ & $\begin{array}{c}\mathrm{T}_{\text {sol,in,de }} \\
\left({ }^{\circ} \mathrm{C}\right)\end{array}$ & $\begin{array}{c}\mathrm{C}_{\mathrm{sol}, \text { in,de }} \\
(\%)\end{array}$ & $\begin{array}{c}\mathrm{T}_{\text {air,in,de }} \\
\left({ }^{\circ} \mathrm{C}\right)\end{array}$ & $\begin{array}{c}\mathrm{W}_{\text {air,in,de }} \\
(\mathrm{kg} / \mathrm{kg})\end{array}$ & $\varepsilon_{\text {lat,num }}$ & $\varepsilon_{\text {lat,exp }}$ & $\begin{array}{c}\text { Error } \\
(\%)\end{array}$ \\
\hline 1 & 4 & 0.009 & - & 25 & 39 & 28 & 0.012 & 0.2837 & 0.251 & 11.526 \\
\hline 4 & 4 & 0.009 & - & 25 & 39 & 28 & 0.012 & 0.7436 & 0.708 & 4.788 \\
\hline 8 & 4 & 0.009 & - & 25 & 39 & 28 & 0.012 & 0.9342 & 0.850 & 9.013 \\
\hline 1 & 4 & 0.012 & - & 25 & 39 & 28 & 0.012 & 0.2853 & 0.249 & 12.723 \\
\hline 4 & 4 & 0.012 & - & 25 & 39 & 28 & 0.012 & 0.7353 & 0.682 & 7.249 \\
\hline 8 & 4 & 0.012 & - & 25 & 39 & 28 & 0.012 & 0.9230 & 0.833 & 9.751 \\
\hline 4 & 1 & 0.009 & - & 25 & 39 & 28 & 0.012 & 0.7466 & 0.702 & 5.974 \\
\hline 4 & 4 & 0.009 & - & 25 & 39 & 28 & 0.012 & 0.7436 & 0.698 & 6.132 \\
\hline 4 & 8 & 0.009 & - & 25 & 39 & 28 & 0.012 & 0.7433 & 0.678 & 8.785 \\
\hline 4 & 1 & 0.012 & - & 25 & 39 & 28 & 0.012 & 0.7411 & 0.699 & 5.681 \\
\hline 4 & 4 & 0.012 & - & 25 & 39 & 28 & 0.012 & 0.7353 & 0.702 & 4.529 \\
\hline 4 & 8 & 0.012 & - & 25 & 39 & 28 & 0.012 & 0.7346 & 0.676 & 7.977 \\
\hline 4 & 4 & 0.0056 & 1 & 25 & 39 & 28 & 0.012 & 0.7247 & 0.689 & 4.926 \\
\hline 4 & 4 & 0.0112 & 2 & 25 & 39 & 28 & 0.012 & 0.7421 & 0.718 & 3.248 \\
\hline 4 & 4 & 0.0224 & 4 & 25 & 39 & 28 & 0.012 & 0.7066 & 0.667 & 5.604 \\
\hline 6 & 6 & 0.0037 & 1 & 25 & 39 & 28 & 0.012 & 0.8253 & 0.790 & 4.278 \\
\hline 6 & 6 & 0.0074 & 2 & 25 & 39 & 28 & 0.012 & 0.8722 & 0.831 & 4.724 \\
\hline 6 & 6 & 0.0148 & 4 & 25 & 39 & 28 & 0.012 & 0.8433 & 0.807 & 4.305 \\
\hline 4 & 4 & 0.0056 & 1 & 25 & 30 & 28 & 0.012 & 0.7167 & 0.674 & 5.958 \\
\hline 4 & 4 & 0.0056 & 1 & 25 & 36 & 28 & 0.012 & 0.7402 & 0.697 & 5.836 \\
\hline 4 & 4 & 0.0056 & 1 & 25 & 42 & 28 & 0.012 & 0.7552 & 0.720 & 0.661 \\
\hline 4 & 4 & 0.0056 & 1 & 25 & 39 & 28 & 0.01 & 0.7616 & 0.728 & 4.412 \\
\hline 4 & 4 & 0.0056 & 1 & 25 & 39 & 30 & 0.01 & 0.7548 & 0.719 & 4.743 \\
\hline 4 & 4 & 0.0056 & 1 & 25 & 39 & 34 & 0.01 & 0.7403 & 0.695 & 6.120 \\
\hline 4 & 4 & 0.0056 & 1 & 25 & 39 & 28 & 0.015 & 0.7530 & 0.715 & 5.047 \\
\hline 4 & 4 & 0.0056 & 1 & 25 & 39 & 30 & 0.015 & 0.7482 & 0.708 & 5.373 \\
\hline 4 & 4 & 0.0056 & 1 & 25 & 39 & 34 & 0.015 & 0.7380 & 0.687 & 6.911 \\
\hline 4 & 4 & 0.0056 & 1 & 25 & 39 & 28 & 0.02 & 0.7446 & 0.687 & 7.738 \\
\hline 4 & 4 & 0.0056 & 1 & 25 & 39 & 30 & 0.02 & 0.7407 & 0.700 & 5.495 \\
\hline 4 & 4 & 0.0056 & 1 & 25 & 39 & 34 & 0.02 & 0.7322 & 0.674 & 0.949 \\
\hline \multicolumn{8}{|c|}{ Operating conditions } & \multicolumn{3}{|c|}{ Comparisons } \\
\hline $\mathrm{NTU}_{\mathrm{de}}$ & $\mathrm{NTU}_{\mathrm{re}}$ & $\begin{array}{c}\mathrm{m}_{\mathrm{sol}} \\
(\mathrm{kg} / \mathrm{s})\end{array}$ & $\mathrm{m}^{*}$ & $\begin{array}{c}\mathrm{T}_{\text {sol,in,de }} \\
\left({ }^{\circ} \mathrm{C}\right)\end{array}$ & $\begin{array}{c}\mathrm{C}_{\mathrm{sol}, \text { in,de }} \\
(\%)\end{array}$ & $\begin{array}{c}\mathrm{T}_{\text {air,in,de }} \\
\left({ }^{\circ} \mathrm{C}\right)\end{array}$ & $\begin{array}{c}\mathrm{W}_{\text {air,in,de }} \\
(\mathrm{kg} / \mathrm{kg})\end{array}$ & $\Theta_{\text {moisture,num }}$ & $\Theta_{\text {moisture,exp }}$ & $\begin{array}{c}\text { Error } \\
(\%)\end{array}$ \\
\hline 1 & 4 & 0.009 & - & 25 & 39 & 28 & 0.012 & 0.0082 & 0.0073 & 10.976 \\
\hline
\end{tabular}




\begin{tabular}{|c|c|c|c|c|c|c|c|c|c|c|}
\hline 4 & 4 & 0.009 & - & 25 & 39 & 28 & 0.012 & 0.0055 & 0.0048 & 12.727 \\
\hline 8 & 4 & 0.009 & - & 25 & 39 & 28 & 0.012 & 0.0035 & 0.0031 & 11.429 \\
\hline 1 & 4 & 0.012 & - & 25 & 39 & 28 & 0.012 & 0.0078 & 0.0068 & 12.821 \\
\hline 4 & 4 & 0.012 & - & 25 & 39 & 28 & 0.012 & 0.0052 & 0.0046 & 11.539 \\
\hline 8 & 4 & 0.012 & - & 25 & 39 & 28 & 0.012 & 0.0033 & 0.0029 & 12.121 \\
\hline 4 & 1 & 0.009 & - & 25 & 39 & 28 & 0.012 & 0.0056 & 0.0049 & 12.500 \\
\hline 4 & 4 & 0.009 & - & 25 & 39 & 28 & 0.012 & 0.0055 & 0.0048 & 12.727 \\
\hline 4 & 8 & 0.009 & - & 25 & 39 & 28 & 0.012 & 0.0055 & 0.0049 & 10.910 \\
\hline 4 & 1 & 0.012 & - & 25 & 39 & 28 & 0.012 & 0.0053 & 0.0048 & 9.434 \\
\hline 4 & 4 & 0.012 & - & 25 & 39 & 28 & 0.012 & 0.0052 & 0.0046 & 11.539 \\
\hline 4 & 8 & 0.012 & - & 25 & 39 & 28 & 0.012 & 0.0051 & 0.0045 & 11.765 \\
\hline 4 & 4 & 0.0056 & 1 & 25 & 39 & 28 & 0.012 & 0.0055 & 0.0049 & 10.910 \\
\hline 4 & 4 & 0.0112 & 2 & 25 & 39 & 28 & 0.012 & 0.0052 & 0.0051 & 1.923 \\
\hline 4 & 4 & 0.0224 & 4 & 25 & 39 & 28 & 0.012 & 0.0045 & 0.0046 & -2.223 \\
\hline 6 & 6 & 0.0037 & 1 & 25 & 39 & 28 & 0.012 & 0.0041 & 0.0038 & 7.317 \\
\hline 6 & 6 & 0.0074 & 2 & 25 & 39 & 28 & 0.012 & 0.0044 & 0.0039 & 11.364 \\
\hline 6 & 6 & 0.0148 & 4 & 25 & 39 & 28 & 0.012 & 0.0038 & 0.0034 & 10.526 \\
\hline 4 & 4 & 0.0056 & 1 & 25 & 30 & 28 & 0.012 & 0.0042 & 0.0037 & 11.905 \\
\hline 4 & 4 & 0.0056 & 1 & 25 & 36 & 28 & 0.012 & 0.0051 & 0.0046 & 9.804 \\
\hline 4 & 4 & 0.0056 & 1 & 25 & 42 & 28 & 0.012 & 0.0058 & 0.0053 & 8.621 \\
\hline 4 & 4 & 0.0056 & 1 & 25 & 39 & 28 & 0.01 & 0.0033 & 0.0029 & 12.121 \\
\hline 4 & 4 & 0.0056 & 1 & 25 & 39 & 30 & 0.01 & 0.0032 & 0.0029 & 9.375 \\
\hline 4 & 4 & 0.0056 & 1 & 25 & 39 & 34 & 0.01 & 0.0032 & 0.0028 & 12.500 \\
\hline 4 & 4 & 0.0056 & 1 & 25 & 39 & 28 & 0.015 & 0.0055 & 0.0051 & 7.273 \\
\hline 4 & 4 & 0.0056 & 1 & 25 & 39 & 30 & 0.015 & 0.0054 & 0.0048 & 11.112 \\
\hline 4 & 4 & 0.0056 & 1 & 25 & 39 & 34 & 0.015 & 0.0054 & 0.0047 & 12.963 \\
\hline 4 & 4 & 0.0056 & 1 & 25 & 39 & 28 & 0.02 & 0.0077 & 0.0072 & 6.494 \\
\hline 4 & 4 & 0.0056 & 1 & 25 & 39 & 30 & 0.02 & 0.0076 & 0.0070 & 7.895 \\
\hline 4 & 4 & 0.0056 & 1 & 25 & 39 & 34 & 0.02 & 0.0075 & 0.0070 & 6.667 \\
\hline
\end{tabular}

\section{Results and discussion}

\subsection{Temperature and humidity (concentration) fields}

Temperature and humidity fields in the air channel, and temperature and concentration fields in the solution channel can be obtained once all governing equations have converged. It is important to clarify temperature and humidity fields for the air and solution in the dehumidifier, temperature and concentration fields for the solution in the regenerator, and temperature and humidity fields on the membrane surfaces in both the dehumidifier and regenerator as these fields reflect the internal processes. These fields are shown in Fig. 6. 


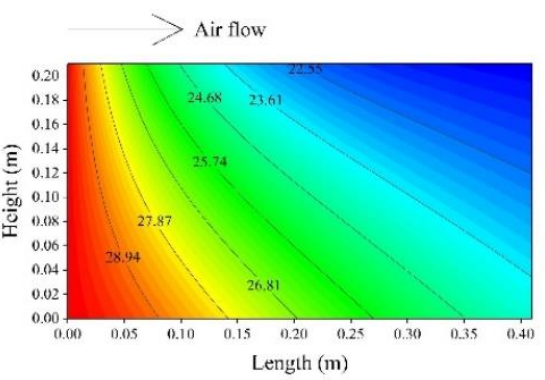

(a)

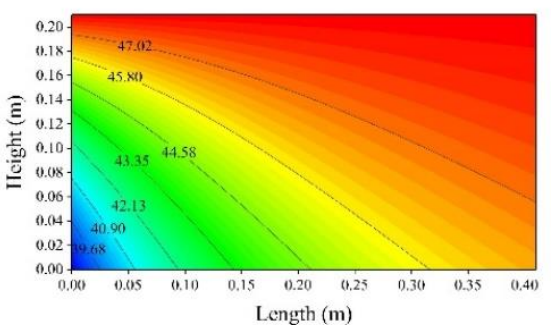

(c)

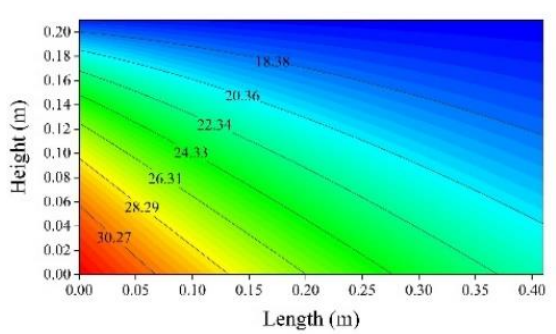

(e)

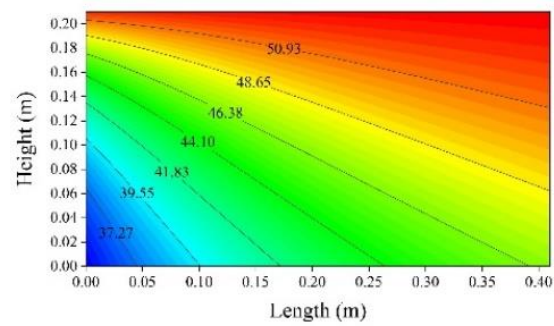

(g)
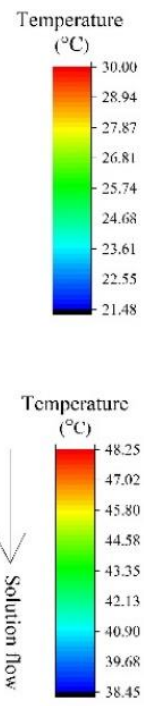

Temperature

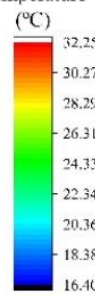

Temperature

( $\left.{ }^{\circ} \mathrm{C}\right)$

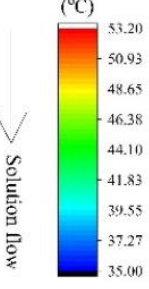

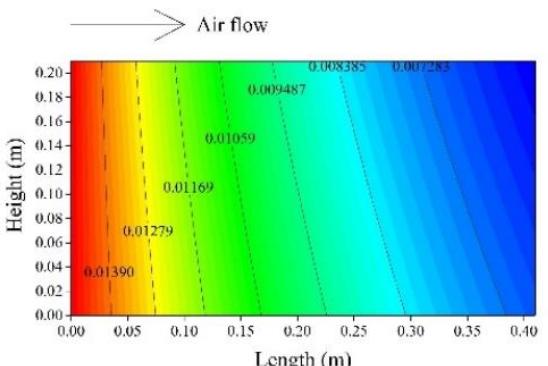

Humidity ratio (kg/kg dry air)

${ }_{-0.01390}^{0.01500}$

(b)
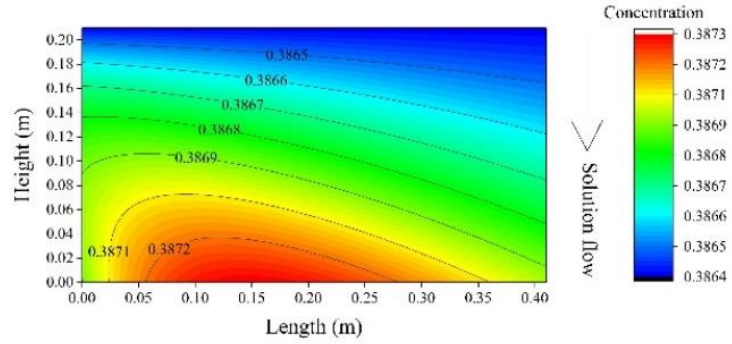

(d)

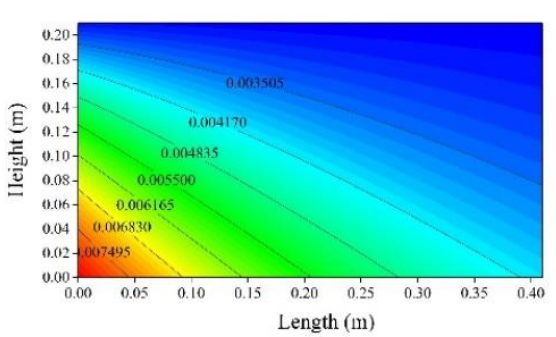

IUumidity ratio (kykg dry air)

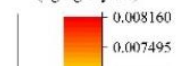

-0.006165
0.005500

$\stackrel{6}{5} \quad 0.0048 \times 35$

产 -0.001170

(f)

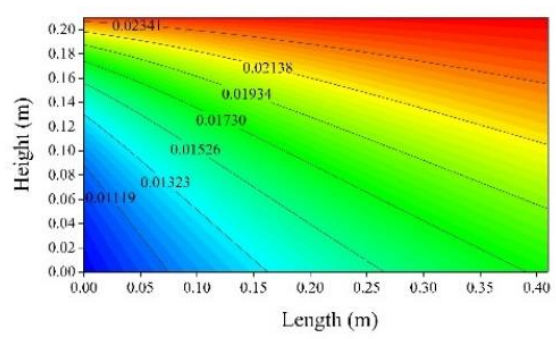

(h)

Fig. 6. Air temperature and humidity ratio fields in dehumidifier (a) (b); solution temperature and concentration fields in regenerator (c) (d); temperature and humidity ratio fields on membrane surface in dehumidifier (e) (f); temperature and humidity ratio fields on membrane surface in regenerator $(\mathrm{g})(\mathrm{h})$

Fig. 6 is plotted under $N T U_{d e}=N T U_{r e}=4$ and $m^{*}=1\left(\dot{m}_{s o l}=0.0056 \mathrm{~kg} / \mathrm{s}\right)$ condition. The solution inlet temperature and concentration in the dehumidifier are $25^{\circ} \mathrm{C}$ and $39 \%$ respectively, the air inlet temperature and humidity ratio in the dehumidifier are $30^{\circ} \mathrm{C}$ and 0.015 $\mathrm{kg} / \mathrm{kg}$ dry air respectively, the return air from indoor environment for regeneration is at state of $28^{\circ} \mathrm{C}$ and $0.012 \mathrm{~kg} / \mathrm{kg}$ dry air. It can be seen from Fig. 6 (a) and (b) that the air temperature and humidity ratio have similar distribution in the dehumidifier as they both decrease diagonally from the left bottom corner to the right upper corner. This is because the air is cooled and dehumidified when contacting with the solution along the length of the dehumidifier. 
Moreover, the solution is warmed and diluted by the air along the height of the dehumidifier, thus the air at the right upper corner has the lowest temperature and humidity ratio. For the solution temperature distribution in the regenerator as illustrated in Fig. 6(c), the solution enters the regenerator with a relatively high temperature $\left(48.25^{\circ} \mathrm{C}\right.$ under this operating condition) as it is heated by hot water, then it is cooled by the return air, and its average outlet temperature is $41.01^{\circ} \mathrm{C}$. The solution temperature decreases along the diagonal line of the regenerator, from the right upper corner to the left bottom corner. With regard to the solution concentration distribution as shown in Fig. 6(d), the solution enters the regenerator with a relatively low concentration after the dehumidification process, it is re-concentrated in the regenerator. Unlike the diagonal change for other property distributions, there is a nearly semicircle zoom at the bottom of the solution concentration field. This is caused by the effects of moisture transfer and phase change in the regenerator as the latent heat is taken away from the solution channel in the process of water evaporation. The latent heat is assumed to be taken only from the solution side since convective mass transfer coefficient of the desiccant solution $\left(h_{m, s o l}\right)$ is much higher than that of the air $\left(h_{m, a i r}\right)$. Based on the governing equations for the regenerator, heat transfer and mass transfer are closely related to each other, this leads to the semi-circular contour lines in the solution concentration field. The temperature and equilibrium humidity ratio boundary conditions on the membrane surfaces of the dehumidifier and regenerator are displayed in Fig. 6(e) (f) (g) and (h), they are neither uniform temperature nor uniform humidity ratio distribution. The temperature and equilibrium humidity ratio increase from the right upper corner to the left bottom corner in the dehumidifier, by contrast, they decrease along the same direction in the regenerator. To sum up, the contours are both two-dimensional and non-uniform, and they all vary along the diagonal line of the membrane surface.

\subsection{Effects of dimensionless parameters}

The effects of system dimensionless parameters (the dehumidifier side $N T U_{d e}$, regenerator side $N T U_{r e}$, and mass flow rate ratio $\mathrm{m}^{*}$ ) on the complete system dehumidification performance are evaluated by the system sensible and latent effectiveness $\varepsilon_{\text {sen,sys }}, \varepsilon_{\text {lat,sys }}$ and moisture flux rate $\Theta_{\text {moisture }}$, while the system energy performance is assessed by the total cooling capacity $Q_{\text {cooling }}$ and coefficient of performance $C O P$.

\subsubsection{Effect of the dehumidifier side $N T U_{d e}$}

The variations of $\varepsilon_{\text {sen,sys }}, \varepsilon_{\text {lat,sys }}$ and $\Theta_{\text {moisture }}$ with $N T U_{d e}$ under different solution mass flow rates are plotted in Figs. 7-9. 


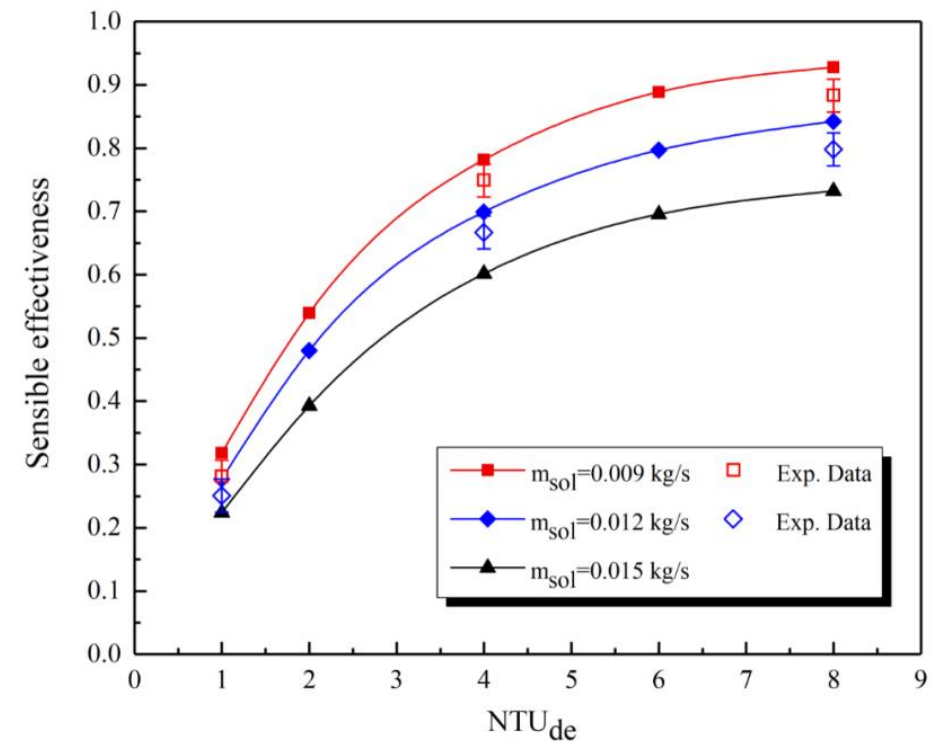

Fig. 7. System sensible effectiveness variations against $N T U_{d e}$ under various $\dot{m}_{\text {sol }}$

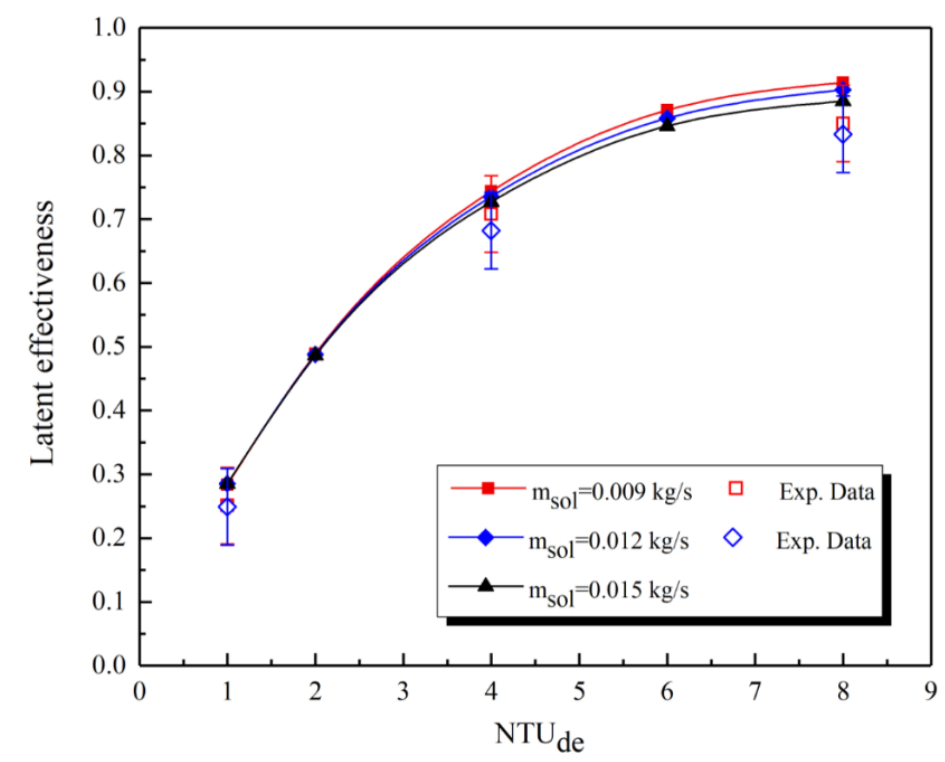

Fig. 8. System latent effectiveness variations against $N T U_{d e}$ under various $\dot{m}_{s o l}$ 


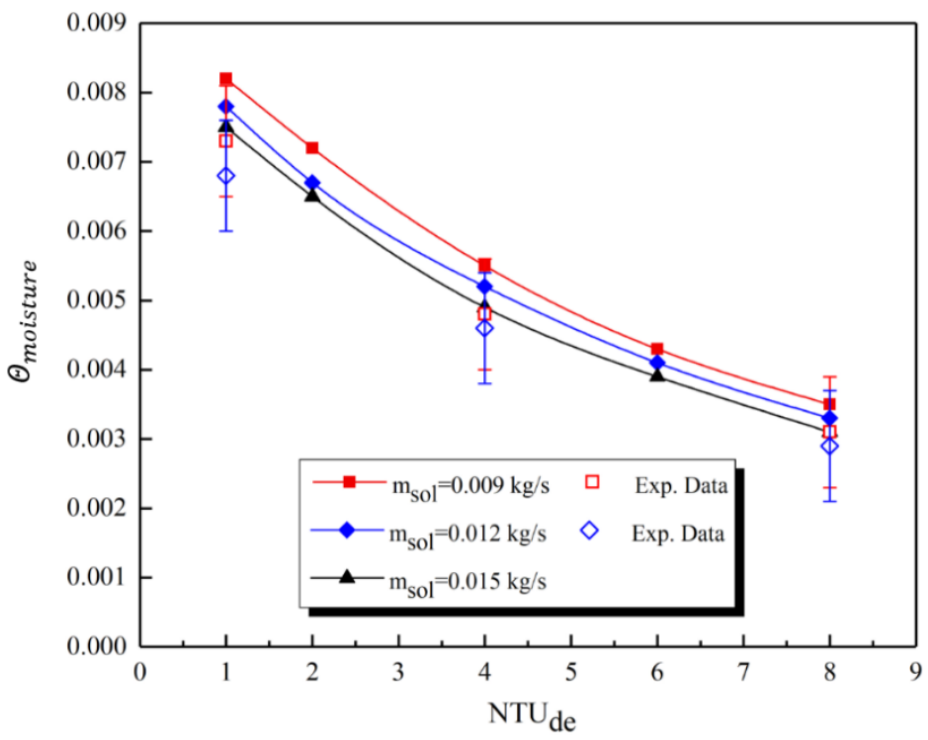

Fig. 9. Moisture flux rate variations against $N T U_{d e}$ under various $\dot{m}_{\text {sol }}$

$N T U$ has been used in many literature previously to assess the performance of heat and mass exchanger. In this study, according to Eq. (18) for a given system with the fixed sizes of the dehumidifier and regenerator, $N T U_{d e}$ is adjusted by changing air mass flow rate through the dehumidifier. $N T U_{d e}$ is inversely proportional to $\dot{m}_{a i r, d e}$, for example, $\dot{m}_{a i r, d e}$ decreases from $0.0224 \mathrm{~kg} / \mathrm{s}$ to $0.0028 \mathrm{~kg} / \mathrm{s}$ when $N T U_{d e}$ increases from 1 to 8 . In the meanwhile, $N T U_{r e}$ is kept at $4\left(\dot{m}_{\text {air, } r e}=0.0056 \mathrm{~kg} / \mathrm{s}\right)$.

As shown in Figs. 7 and 8, both $\varepsilon_{s e n, s y s}$ and $\varepsilon_{\text {lat,sys }}$ increase with $N T U_{d e}$. For example, under $\dot{m}_{\text {air,re }}=0.015 \mathrm{~kg} / \mathrm{s}, \varepsilon_{\text {sen,sys }}$ increases from 0.2237 to 0.7422 when $N T U_{d e}$ changes from 1 to 8 , while $\varepsilon_{\text {lat,sys }}$ increases from 0.2852 to 0.9049 . However, their increase gradients reduce with $N T U_{d e}$ gradually, and finally level off. For example, under $\dot{m}_{s o l}=0.009 \mathrm{~kg} / \mathrm{s}, \varepsilon_{\text {sen,sys }}$ increases by $179.11 \%$ from 0.3184 to 0.8887 when $N T U_{d e}$ changes from 1 to 6 . When $N T U_{d e}$ further increases from 6 to $8, \varepsilon_{\text {sen,sys }}$ only rises by $5.54 \%$ from 0.8887 to 0.9379 . The same situation is for $\varepsilon_{\text {lat,sys }}$, under $\dot{m}_{\text {sol }}=0.009 \mathrm{~kg} / \mathrm{s}, \varepsilon_{\text {lat,sys }}$ rises by $207.01 \%$ from 0.2837 to 0.871 when $N T U_{d e}$ changes from 1 to 6 . And it only increases by $7.26 \%$ from 0.871 to 0.9342 when $N T U_{d e}$ varies from 6 to 8 . Thus similar to single dehumidifier or regenerator, a critical dehumidifier side $N T U$ does exist and can be defined as $N T U_{d e, c r i t}$. In this case $N T U_{d e, c r i t}$ is equal to 6 . Before $N T U_{d e}$ reaches 6 , both $\varepsilon_{s e n, s y s}$ and $\varepsilon_{\text {lat,sys }}$ can be improved by increasing $N T U_{d e}$, but increasing $N T U_{d e}$ over $N T U_{d e, c r i t}$ would not enhance $\varepsilon_{s e n, s y s}$ and $\varepsilon_{\text {lat,sys }}$.

It is also noticed from Figs. 7 and 8 that $\varepsilon_{\text {sen,sys }}$ is not always higher than $\varepsilon_{\text {lat,sys }}$. Under $\dot{m}_{\text {sol }}=0.009 \mathrm{~kg} / \mathrm{s}$ and $0.012 \mathrm{~kg} / \mathrm{s}, \varepsilon_{\text {sen,sys }}$ is higher than $\varepsilon_{\text {lat,sys }}$ for all $N T U_{d e}$. For instance, under $\dot{m}_{\text {sol }}=0.012 \mathrm{~kg} / \mathrm{s}, \varepsilon_{\text {sen,sys }}$ increases from 0.2769 to 0.8525 when $N T U_{d e}$ varies from 1 to 8 ,, while $\varepsilon_{\text {lat,sys }}$ changes from 0.2853 to 0.9230 . However, once $\dot{m}_{\text {sol }}$ reaches 
$0.015 \mathrm{~kg} / \mathrm{s}, \varepsilon_{\text {lat,sys }}$ is higher than $\varepsilon_{s e n, s y s}$ for all $N T U_{d e}$. For instance, under $\dot{m}_{\text {sol }}=$ $0.015 \mathrm{~kg} / \mathrm{s}, \varepsilon_{\text {sen,sys }}$ only increases from 0.2237 to 0.7422 when $N T U_{d e}$ changes from 1 to 8 , while $\varepsilon_{\text {lat,sys }}$ increases from 0.2852 to 0.9049 .

The moisture flux rate $\Theta_{\text {moisture }}$ is another dimensionless parameter used to evaluate the dehumidification ability. It reflects the total moisture being absorbed by the solution. As indicated in Fig. 9, $\Theta_{\text {moisture }}$ decreases with $N T U_{d e}$ under all $\dot{m}_{s o l}$. This is because $N T U_{d e}$ is inversely proportional to $\dot{m}_{a i r, d e}$, the increase of $N T U_{d e}$ can be achieved by reducing the air flow rate through the dehumidifier. Although the dehumidification effectiveness is improved, and the air humidity ratio at the outlet of the dehumidifier is reduced (for instance, under $\dot{m}_{\text {sol }}=0.009 \mathrm{~kg} / \mathrm{s}, W_{\text {air }, \text { out }, \text { de }}$ is reduced from 0.0136 to $0.0041 \mathrm{~kg} / \mathrm{kg}$ dry air when $N T U_{d e}$ changes from 1 to 8 ), the total amount of moisture being absorbed is still decreased. Apart from dehumidification effect, it is of our interest to evaluate the energy performance of the complete system as well. The relationships among $N T U_{d e}, Q_{\text {cooling }}$ and $C O P$ under different solution mass flow rates are given in Figs. 10 and 11.

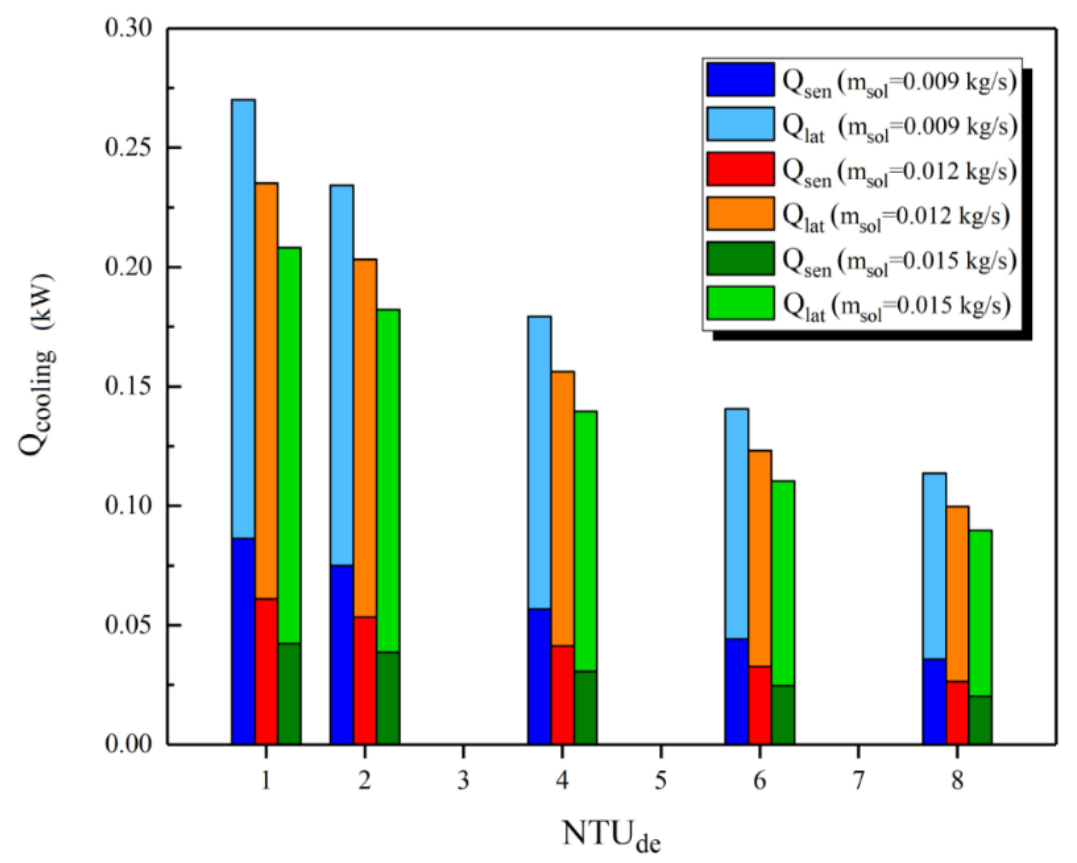

Fig. 10. Total cooling capacity $Q_{\text {cooling }}$ variations against $N T U_{d e}$ under various $\dot{m}_{\text {sol }}$ 


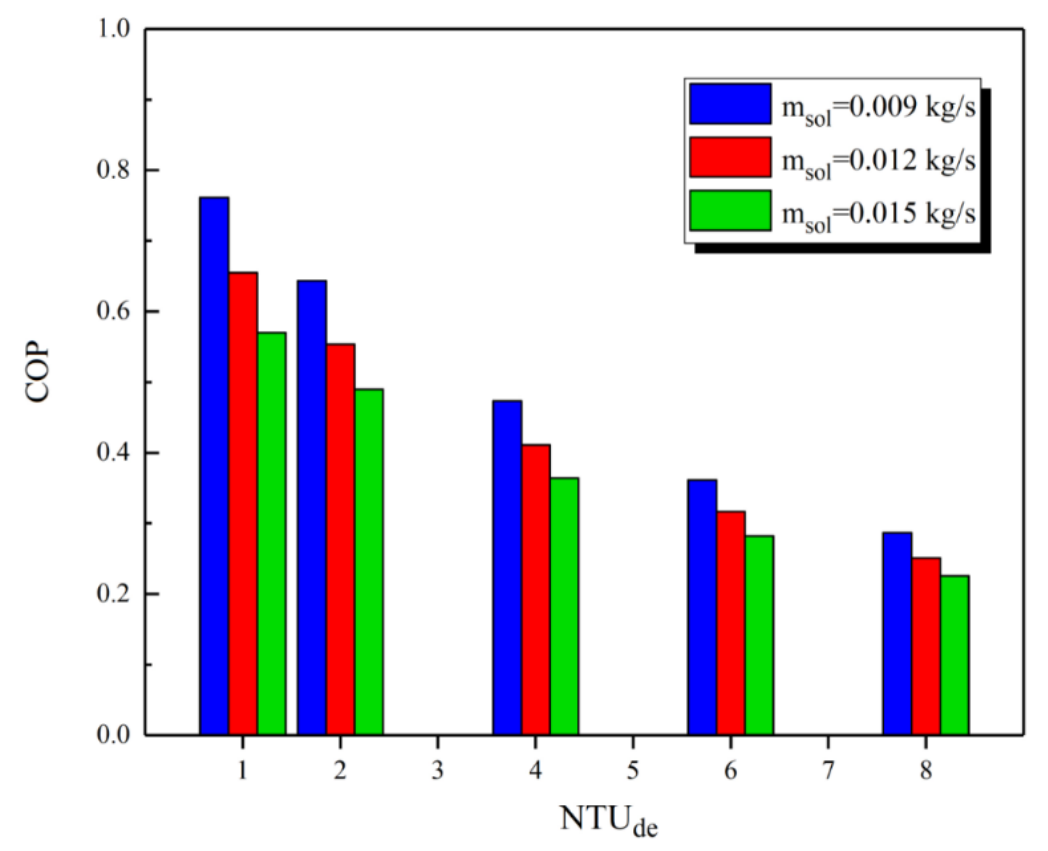

Fig. 11. $C O P$ variations against $N T U_{d e}$ under various $\dot{m}_{\text {sol }}$

As shown in Fig. 10, the latent cooling capacity $Q_{\text {lat }}$ is significantly higher than the sensible cooling capacity $Q_{\text {sen }}$ under all circumstances, in other words the latent cooling capacity accounts for the majority part of the total cooling output. For instance, under $\dot{m}_{s o l}=$ $0.009 \mathrm{~kg} / \mathrm{s}$ and $N T U_{d e}=1$, the sensible cooling capacity is $0.086 \mathrm{~kW}$ while the latent cooling capacity is $0.184 \mathrm{~kW}$, which is two times higher than the sensible cooling capacity. As mentioned in previous study [32], decreasing the solution inlet temperature could improve the cooling effect in the dehumidifier, however for the complete system in reality, sometimes it is not practical to cool the desiccant solution. That is the reason to set the desiccant solution temperature as $25^{\circ} \mathrm{C}$ in this study. As the result, the dehumidifier outlet air temperature is too high to be supplied to conditioned space directly, so further cooling, such as indirect evaporative cooling, is required after dehumidification. Furthermore, under all solution flow rates, the sensible cooling capacity $Q_{s e n}$, latent cooling capacity $Q_{l a t}$ and total cooling capacity $Q_{t o t}$ decrease considerably with $N T U_{d e}$. For example, under $\dot{m}_{s o l}=0.009 \mathrm{~kg} / \mathrm{s}$, when $N T U_{d e}$ increases from 1 to $8, Q_{\text {sen }}$ decreases from $0.086 \mathrm{~kW}$ to $0.036 \mathrm{~kW}, Q_{\text {lat }}$ decreases from $0.184 \mathrm{~kW}$ to $0.078 \mathrm{~kW}$ and $Q_{\text {tot }}$ decreases from $0.270 \mathrm{~kW}$ to $0.114 \mathrm{~kW}$. This is owing to significant decrease of $\dot{m}_{a i r, d e}$ when increasing $N T U_{d e}$. As discussed previously, although the dehumidification effectiveness is improved, the total cooling capacity is limited by dramatic decrease of the air flow rate. Similar results can be noticed from the variations of COP with $N T U_{d e}$ in Fig. 11. Under $\dot{m}_{s o l}=0.009,0.012$ and $0.015 \mathrm{~kg} / \mathrm{s}$, when $N T U_{d e}$ increases from 1 to 8 , the COP decreases from 0.761 to $0.287,0.655$ to 0.251 and 0.570 to 0.226 respectively. Based on the definition of $N T U$ which is given in Eq. (18), for the dehumidifier or regenerator with the fixed geometry (fixed heat and mass transfer area) and solution type, NTU can be only 
changed by adjusting the air flow rate. Thus the moisture flux rate $\Theta_{\text {moisture }}$, total cooling capacity $Q_{\text {cooling }}$ and COP would all reduce with $N T U_{d e}$ even though both the sensible and latent effectiveness of complete system can be improved.

\subsubsection{Effect of the regenerator side $N T U_{\text {re }}$}

Similar to $N T U_{d e}$ effects, the influences of the regenerator side $N T U_{r e}$ are addressed in this section. The variations of $\varepsilon_{\text {sen,sys }}, \varepsilon_{\text {lat,sys }}$ and $\Theta_{\text {moisture }}$ with $N T U_{r e}$ under different solution mass flow rates are plotted in Figs. 12-14.

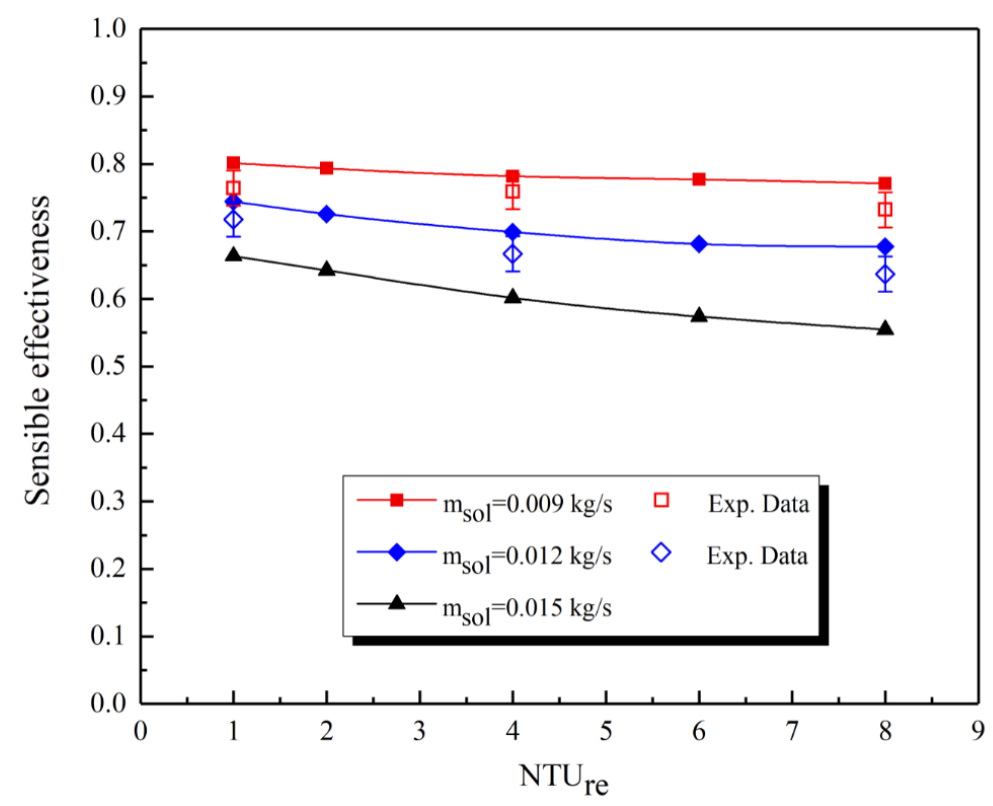

Fig. 12. System sensible effectiveness variations against $N T U_{r e}$ under various $\dot{m}_{s o l}$

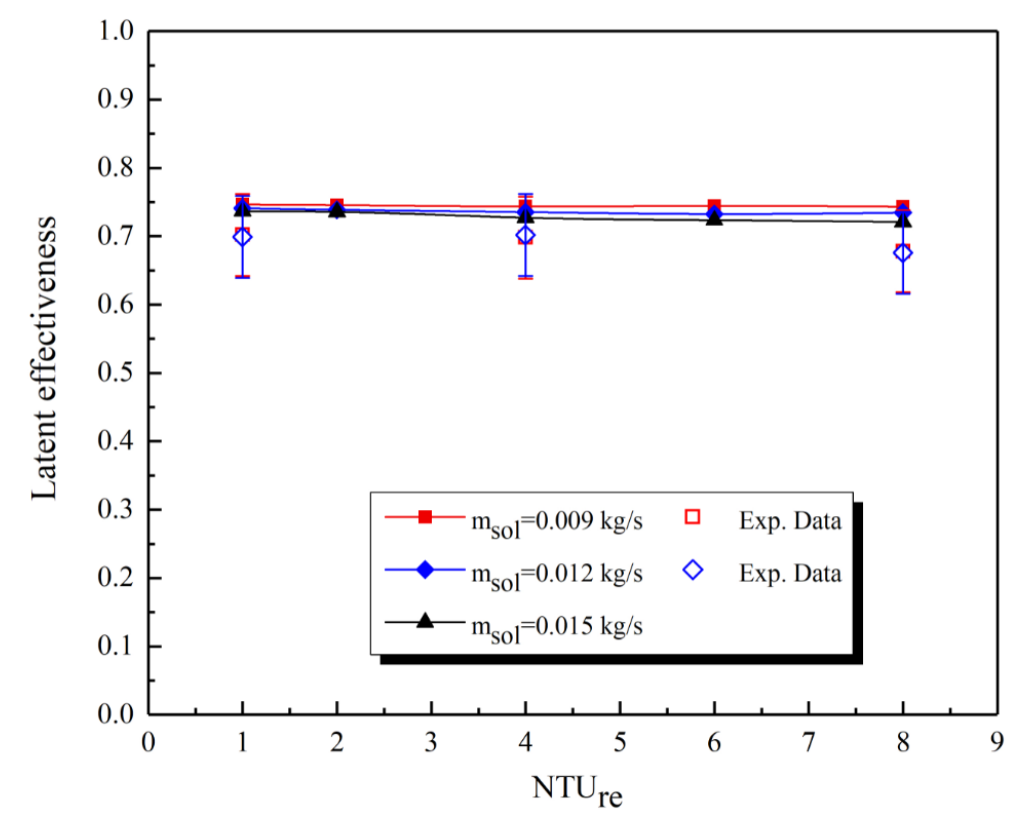

Fig. 13. System latent effectiveness variations against $N T U_{r e}$ under various $\dot{m}_{\text {sol }}$ 


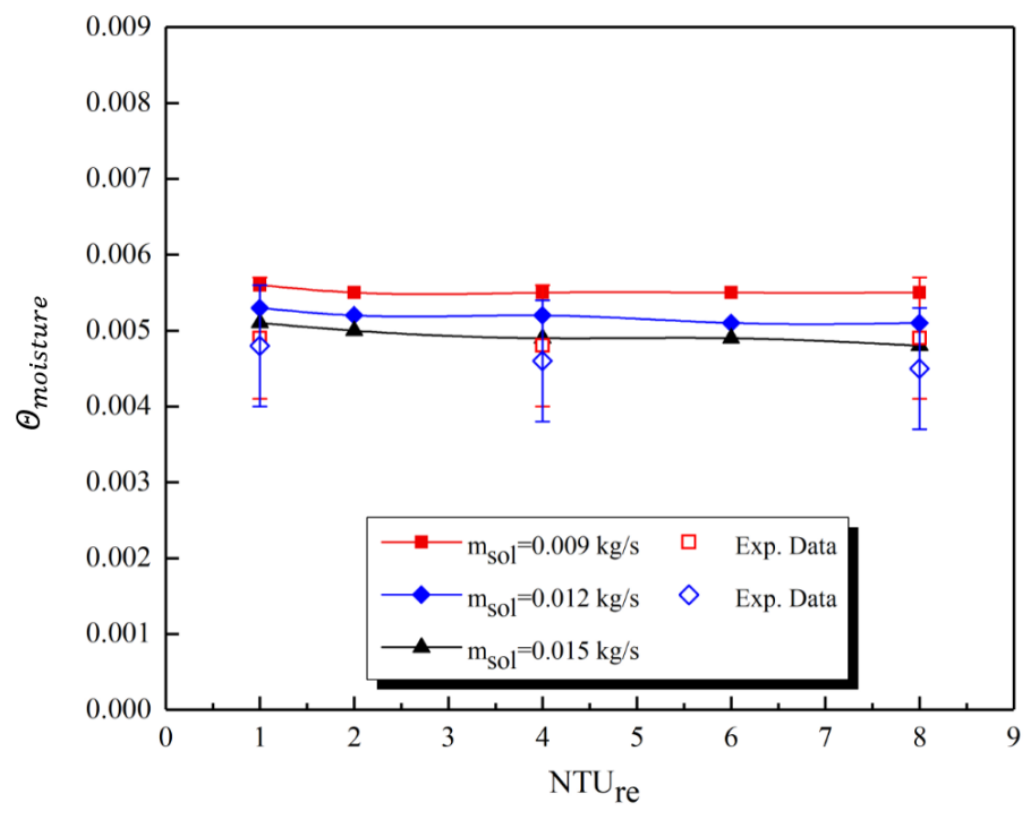

Fig. 14. Moisture flux rate variations against $N T U_{r e}$ under various $\dot{m}_{s o l}$

According to Fig. 12, the influence of $N T U_{r e}$ on the system sensible effectiveness is different from that of $N T U_{d e}$. The system sensible effectiveness decreases with $N T U_{r e}$, and the decrease gradient is more noticeable when $\dot{m}_{s o l}$ is relatively higher. Under $\dot{m}_{s o l}=0.009 \mathrm{~kg} / \mathrm{s}$, $\varepsilon_{s e n, s y s}$ decreases by $3.78 \%$ from 0.801 to 0.771 when $N T U_{r e}$ changes from 1 to 8 , while it reduces by $16.4 \%$ from 0.664 to 0.554 under $\dot{m}_{\text {sol }}=0.015 \mathrm{~kg} / \mathrm{s}$. However, the influence of $N T U_{r e}$ on the system sensible effectiveness is negligible compared with that of $N T U_{d e}$. This is more obvious for the system latent effectiveness and $\Theta_{\text {moisture }}$. It can be seen from Figs. 13 and 14 that neither $\varepsilon_{\text {lat,sys }}$ nor $\Theta_{\text {moisture }}$ has noticeable variation with $N T U_{r e}$. For example, under $\dot{m}_{\text {sol }}=0.009 \mathrm{~kg} / \mathrm{s}, \varepsilon_{\text {lat,sys }}$ only decreases by $0.54 \%$ from 0.747 to 0.743 when $N T U_{\text {re }}$ increases from 1 to 8 . The effect of solution mass flow rate on $\varepsilon_{\text {lat,sys }}$ is negligible as well, when $N T U_{r e}$ changes from 1 to $8, \varepsilon_{\text {lat,sys }}$ reduces by $2.17 \%$ from 0.737 to 0.721 under $\dot{m}_{\text {sol }}=$ $0.015 \mathrm{~kg} / \mathrm{s}$. The similar influence is for the moisture flux rate, for example when $\dot{m}_{\text {sol }}=$ $0.009,0.012$ and $0.015 \mathrm{~kg} / \mathrm{s}, \Theta_{\text {moisture }}$ decreases by $1.79 \%, 3.77 \%$ and $5.77 \%$ respectively. It is interesting that according to previous research [31] on influence of NTU on the regenerator performance, $N T U$ has considerable impact on the sensible and latent performance of the regenerator. This can be considered as a major difference between the regenerator side effectiveness and the system effectiveness. The major interests on the complete system are how much sensible and latent cooling capacities the complete system can provide for a conditioned space during the dehumidification process. The $N T U_{r e}$, which is adjusted by changing the air flow rate through the regenerator, has no obvious effect on the improvement of system sensible and latent cooling performance. 
Furthermore, the variations of $Q_{\text {cooling }}$ and COP with $N T U_{r e}$ under different solution mass flow rates are given in Figs. 15 and 16.

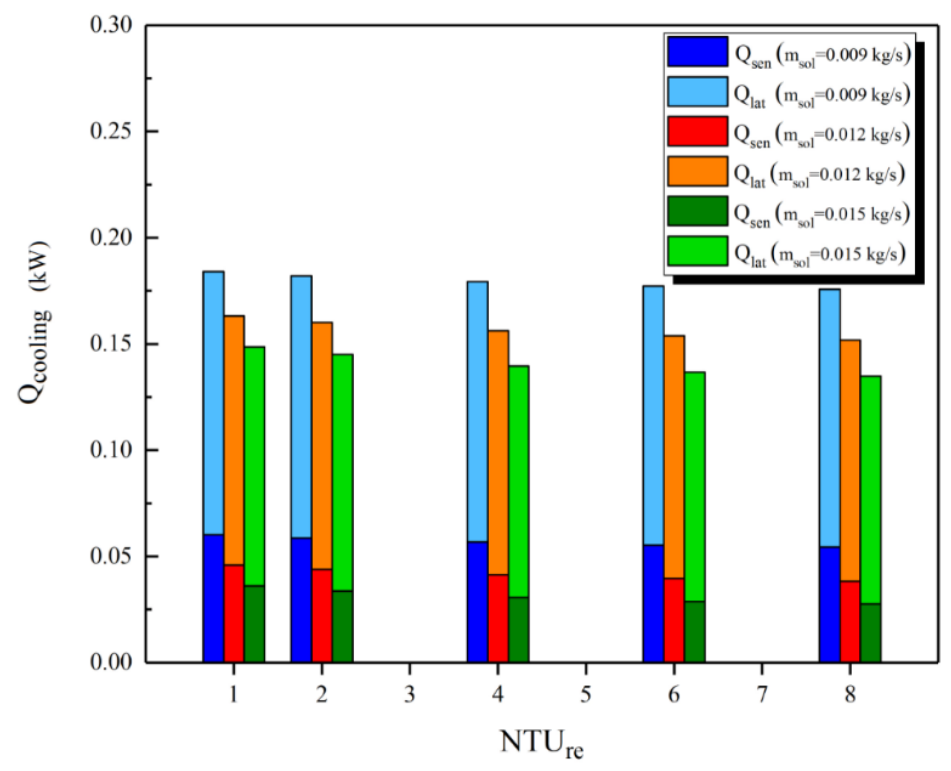

Fig. 15. Total cooling capacity $Q_{\text {cooling }}$ variations against $N T U_{r e}$ under various $\dot{m}_{s o l}$

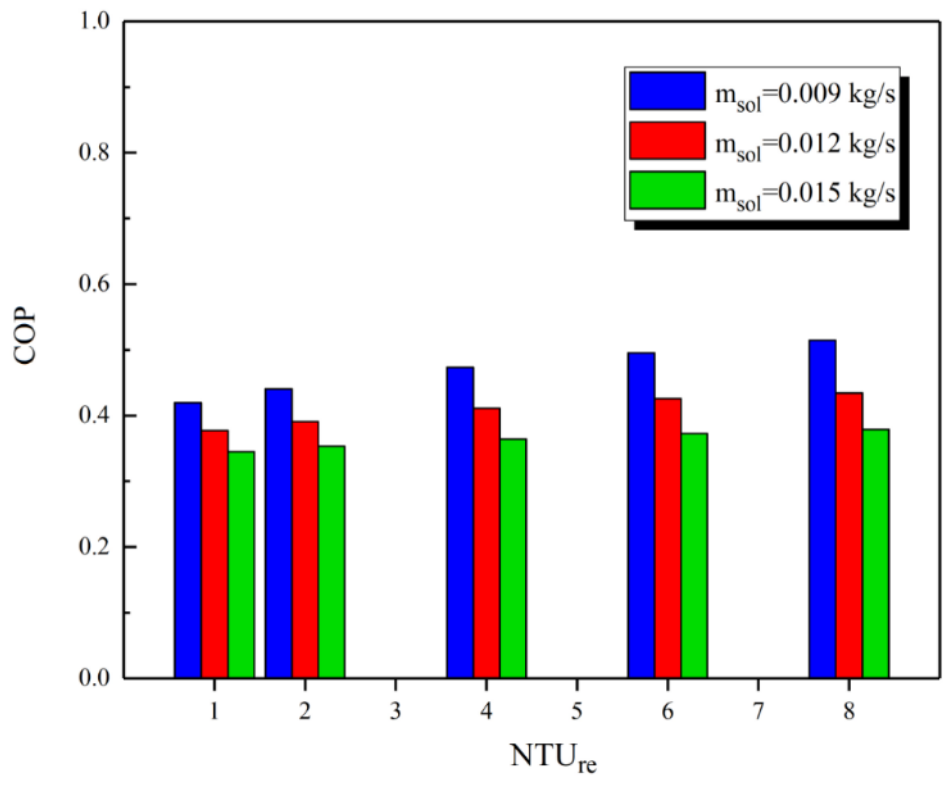

Fig. 16. $C O P$ variations against $N T U_{r e}$ under various $\dot{m}_{\text {sol }}$

Since the air mass flow rate through the dehumidifier remains constant, the sensible and latent cooling capacities are related to the system sensible and latent effectiveness directly, which are illustrated in Figs. 15 and 16. Under $\dot{m}_{\text {sol }}=0.009 \mathrm{~kg} / \mathrm{s}, Q_{\text {sen }}$ decreases from $0.060 \mathrm{~kW}$ to $0.054 \mathrm{~kW}$ when $N T U_{r e}$ increases from 1 to 8 , and this is caused by the decrease of $\varepsilon_{\text {sen,sys }}$. Similarly, since $\varepsilon_{\text {lat,sys }}$ and $\Theta_{\text {moisture }}$ are independent of $N T U_{\text {re }}, Q_{\text {lat }}$ is relatively constant when $N T U_{r e}$ changes. For instance, under $\dot{m}_{s o l}=0.012 \mathrm{~kg} / \mathrm{s}, Q_{\text {lat }}$ only decreases by $5.3 \%$ from 0.113 to 0.107 when $N T U_{r e}$ increases from 1 to 8 . It can be seen that the latent cooling 
capacity again accounts for the majority of the total cooling capacity under all conditions. As the result, the total cooling capacity does not vary significantly with $N T U_{r e}$. As $\dot{m}_{s o l}$ is 0.009 , 0.012 and $0.015 \mathrm{~kg} / \mathrm{s}$, the corresponding $Q_{\text {cooling }}$ decrease by $4.35 \%, 6.75 \%$ and $9.40 \%$ respectively when $N T U_{r e}$ increases from 1 to $8 . N T U_{r e}$ has positive effect on the system COP as displayed in Fig. 16. It is the fact that the total cooling capacity would decrease slightly with $N T U_{r e}$, however the regeneration heat input would decrease as well. This is because increasing the air flow rate through the regenerator would significantly improve the regenerator latent effectiveness, as the result the regeneration of desiccant solution becomes easier and the regeneration energy input is reduced [31]. For $\dot{m}_{s o l}=0.009 \mathrm{~kg} / \mathrm{s}$, with the increase of $N T U_{r e}$ from 1 to $8, Q_{\text {reg }}$ reduces from $0.438 \mathrm{~kW}$ to $0.342 \mathrm{~kW}$ and COP increases from 0.420 to 0.514 . Similarly, for $\dot{m}_{\text {sol }}=0.015 \mathrm{~kg} / \mathrm{s}, Q_{\text {reg }}$ reduces from $0.431 \mathrm{~kW}$ to $0.356 \mathrm{~kW}$ and $C O P$ increases from 0.345 to 0.379 as $N T U_{r e}$ increases from 1 to 8 .

\subsubsection{Effect of mass flow rate ratio $m^{*}$}

$m^{*}$ is one of the important dimensionless parameters affecting the system performance. It is defined in Eq. (15) as the ratio of solution mass flow rate over the air mass flow rate. For the complete system, the solution mass flow rate is constant within the system under the steady operating condition since it is a closed loop. To address the influence of $m^{*}$, the air mass flow rates through the dehumidifier and regenerator are set equal. This is reasonable in practice since according to Fig. 4, the supply air flow rate from the dehumidifier and the return air flow rate from conditioned space to the regenerator are the same. This setting is helpful for the balance of the air in the conditioned space. Following the same method, the variations of $\varepsilon_{s e n, s y s}$, $\varepsilon_{\text {lat,sys }}$ and $\Theta_{\text {moisture }}$ with $m^{*}$ under different $N T U$ values are plotted in Figs. 17-19.

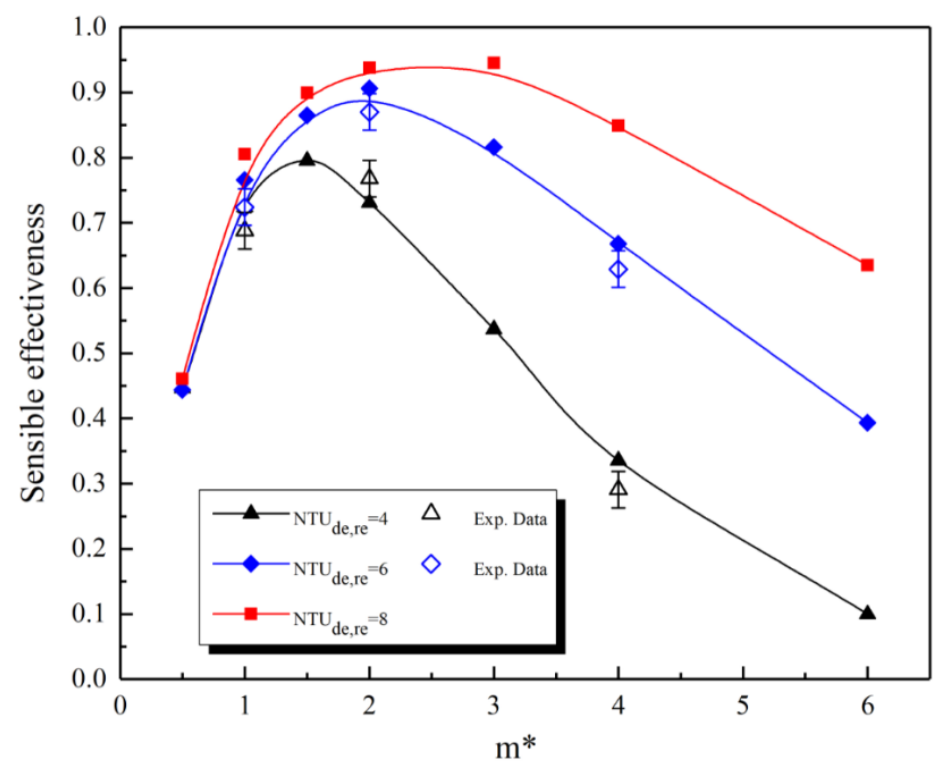

Fig. 17. System sensible effectiveness variations against $m^{*}$ under various $N T U$ 


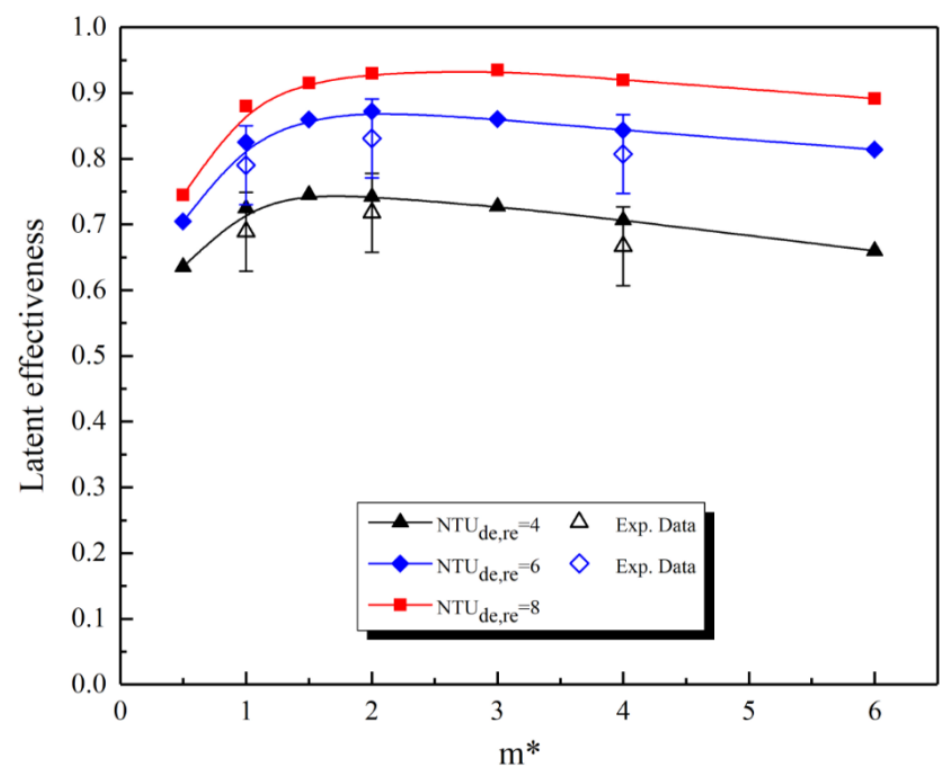

Fig. 18. System latent effectiveness variations against $m^{*}$ under various $N T U$

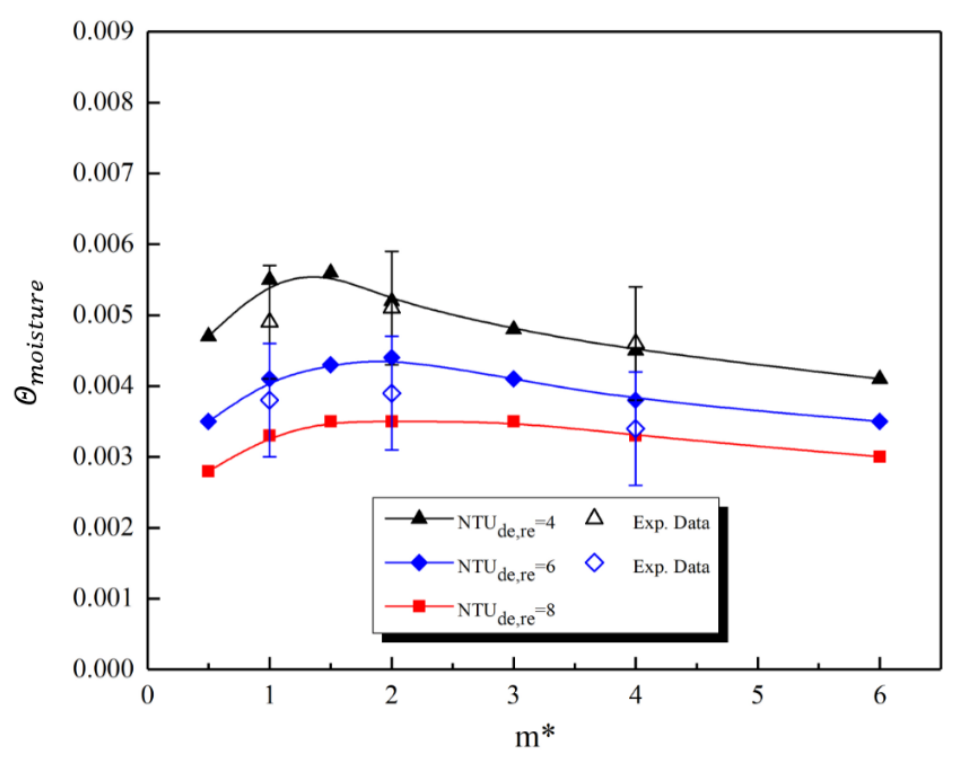

Fig. 19. Moisture flux rate variations against $m^{*}$ under various $N T U$

It can be seen from Fig. 17 that the mass flow rate ratio has very strong impact on the system sensible effectiveness. Generally, it sharply increases with $m^{*}$ at first, and then decreases gradually. Under $N T U_{d e, r e}=4, \varepsilon_{\text {sen,sys }}$ increases from 0.446 to 0.796 when $m^{*}$ varies from 0.5 to 1.5 . When $m^{*}$ keeps increasing to $6, \varepsilon_{\text {sen,sys }}$ gradually decreases from 0.796 to 0.336 . The variation trend is similar to that of $\varepsilon_{s e n, s y s}$ with $N T U_{d e, r e}$. Furthermore, the optimal mass flow rate ratio values, under which the system sensible effectiveness reaches its highest point, are different for various $N T U_{d e, r e}$. Under $N T U_{d e, r e}=4, \varepsilon_{s e n, s y s}$ reaches its highest value of 0.796 when $m^{*}=1.5$. By contrast, it reaches its highest value of 0.906 under $N T U_{d e, r e}=6$ when $m^{*}=2$, and 0.945 under $N T U_{d e, r e}=8$ when $m^{*}=3$. The variation of the system latent effectiveness with $m^{*}$ is comparatively weaker than that of the system sensible effectiveness. 
Similar to the $\varepsilon_{\text {sen,sys }}$ variation, $\varepsilon_{\text {lat,sys }}$ increases with $m^{*}$ before reaching its peak value, and then slowly decreases. The maximum values of $\varepsilon_{\text {lat,sys }}$ under $N T U_{d e, r e}=4,6$ and 8 are 0.745 , 0.872 and 0.935 , and the corresponding $m^{*}$ are $1.5,2$ and 3 respectively. With regard to the moisture flux rate $\Theta_{\text {moisture }}$ as depicted in Fig. 19, it is found that $\Theta_{\text {moisture }}$ under high $N T U_{d e, r e}$ has low value. This has been explained in previous sections as high $N T U_{d e, r e}$ means low air mass flow rate. Even $\varepsilon_{s e n, s y s}$ and $\varepsilon_{\text {lat,sys }}$ would be improved, the total amount of moisture being absorbed would be reduced. Moreover, the variation of $\Theta_{\text {moisture }}$ with $m^{*}$ has very similar trend as those of $\varepsilon_{\text {sen,sys }}$ and $\varepsilon_{\text {lat,sys }}$, it would decrease after reaching the peak value. The variation of $\Theta_{\text {moisture }}$ under $N T U_{d e, r e}=8$ is comparatively weak compared with those under another $N T U_{d e, r e}$ values. It increases from 0.0028 to $0.0035 \mathrm{~kg} / \mathrm{kg}$ dry air when $m^{*}$ changes from 0.5 to 1.5 , then it reduces to $0.003 \mathrm{~kg} / \mathrm{kg}$ dry air when $\mathrm{m}^{*}$ reaches 6 . Under $N T U_{d e, r e}=6$, it peaks at $m^{*}=2$ with the peak value of $0.0044 \mathrm{~kg} / \mathrm{kg}$ dry air, and under $N T U_{d e, r e}=4$, it peaks at $m^{*}=1.5$ with the peak value of $0.0056 \mathrm{~kg} / \mathrm{kg}$ dry air. To sum up, in practice when the air mass flow rate has been determined, there is no benefit by increasing the solution mass flow rate once it's beyond a specific value. To keep increasing the solution mass flow rate would dramatically reduce the system sensible effectiveness, its latent effectiveness and moisture flux rate would be restricted as well. Moreover, the high solution flow rate brings more pump energy input to the system, which would drag down the COP, and this will be discussed later in this section.

Then the variations of $Q_{\text {cooling }}$ and $C O P$ with $m^{*}$ under different $N T U$ values are shown in Figs. 20 and 21.

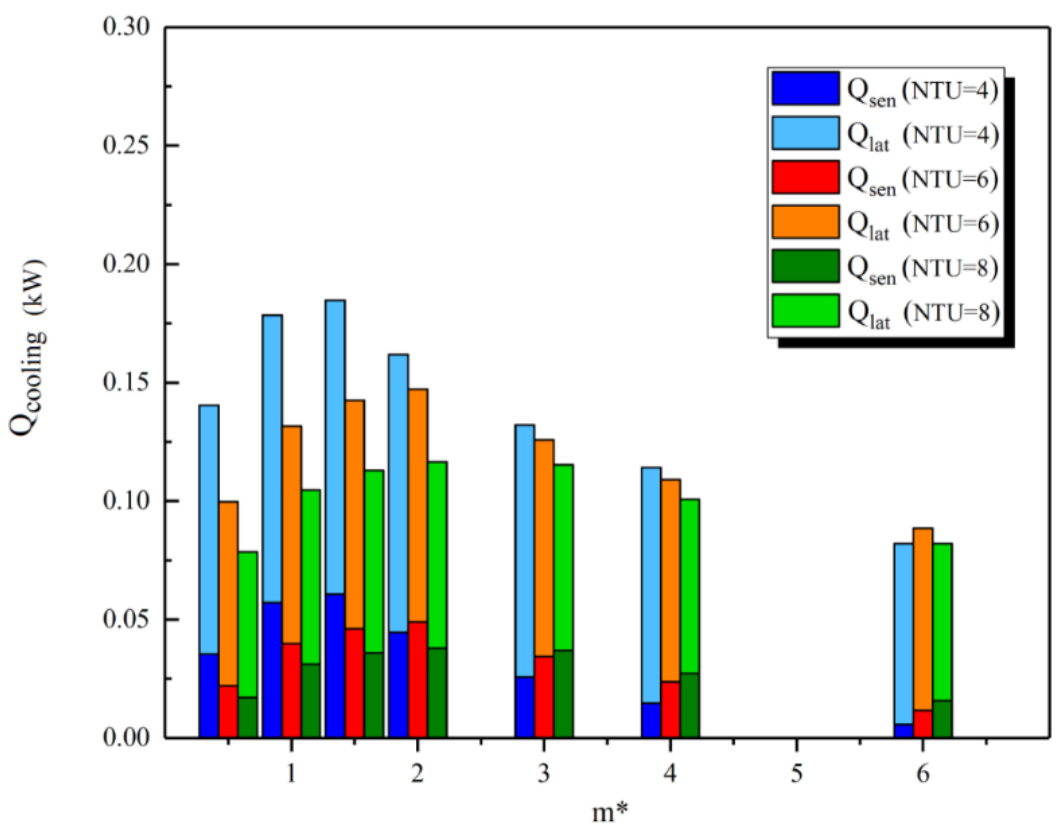

Fig. 20. Total cooling capacity $Q_{\text {cooling }}$ variations against $m^{*}$ under various $N T U$ 


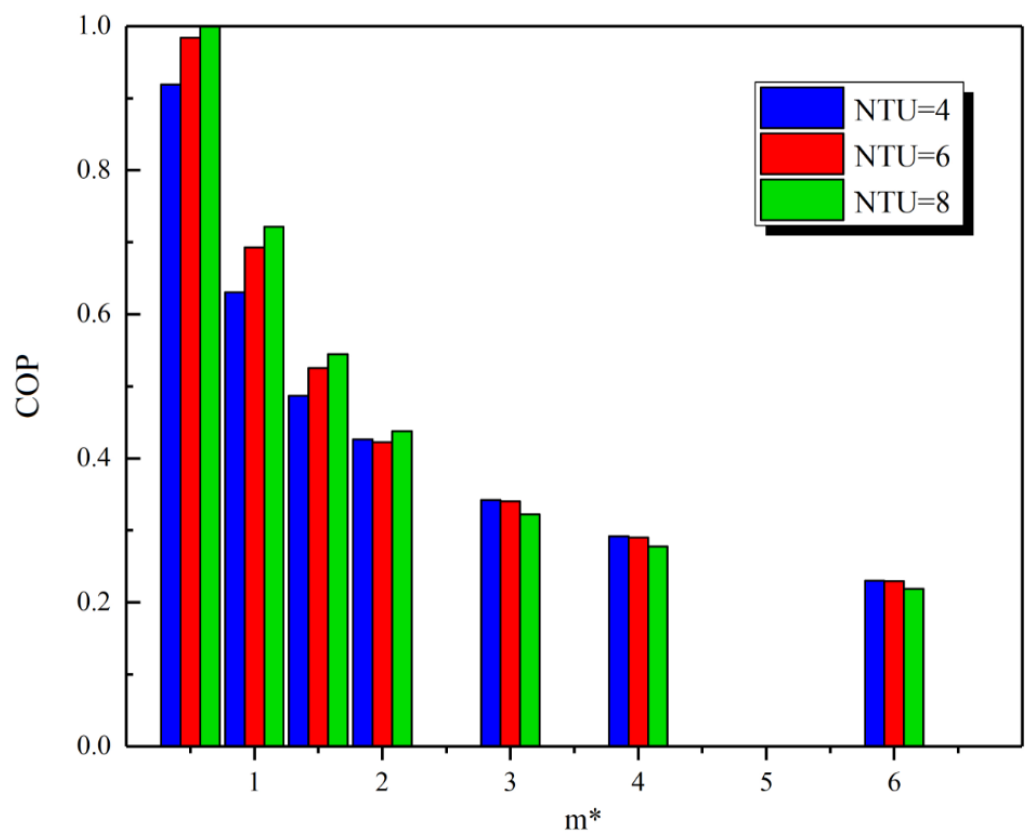

Fig. 21. $C O P$ variations against $m^{*}$ under various $N T U$

As shown in Fig. 20, the latent cooling capacity accounts for the majority of the total cooling capacity as well. The variation of $Q_{\text {cooling }}$ follows the similar trend of the system effectiveness's or moisture flux rate's. For $N T U=4$, when $m^{*}$ changes from 0.5 to 1.5 , $Q_{\text {cooling }}$ increases from $0.140 \mathrm{~kW}$ to its maximum value of $0.185 \mathrm{~kW}$. After that $Q_{\text {cooling }}$ decreases gradually to $0.114 \mathrm{~kW}$. For $N T U=6, Q_{\text {cooling }}$ peaks at $0.147 \mathrm{~kW}$ under $m^{*}=2$, while for $N T U=8$, it peaks at $0.117 \mathrm{~kW}$ under $m^{*}=3$. In other words, the maximum total cooling capacity can be achieved at $m^{*}=1.5$ under $N T U=4$, at $m^{*}=2$ under $N T U=6$ and $m^{*}=3$ under $N T U=8$. However the COP would decline as $m^{*}$ increases from 0.5 to 6 , as shown in Fig. 21. Despite the variation of the cooling capacity with $m^{*}$ is not in one direction, $m^{*}$ has considerable effect on the denominator in Eq. (49). Since the dehumidifier and regenerator side NTUS remain unchanged, so the fan power $W_{f a n}$ is constant. However $m^{*}$ can be enhanced by increasing the solution flow rate in the closed solution loop, which would significantly increase the pump power $W_{\text {pump }}$ and regeneration heat input $Q_{\text {reg }}$. For instance, under $N T U=6, Q_{\text {reg }}$ increases from $0.11 \mathrm{~kW}$ to $0.386 \mathrm{~kW}$ as $\mathrm{m}^{*}$ changes from 0.5 to 6 . This also indicates that increasing $m^{*}$ after excessing a critical value would not enhance the total cooling capacity, the system COP would be deteriorated as well.

\subsection{Effect of solution inlet property}

For the complete system, one of the controllable inputs is the solution inlet concentration in the dehumidifier $C_{\text {sol,in. }}$. The variations of the effectiveness (sensible and latent effectiveness) and moisture flux rate with $C_{s o l, i n}$ are plotted in Fig. 22 when both $N T U_{d e}$ and $N T U_{r e}$ are set as 4 , 
and $m^{*}$ is set as 1 , the changes of $Q_{\text {cooling }}$ and COP with $C_{\text {sol,in }}$ are given in Fig. 23 and Fig. 24 respectively.

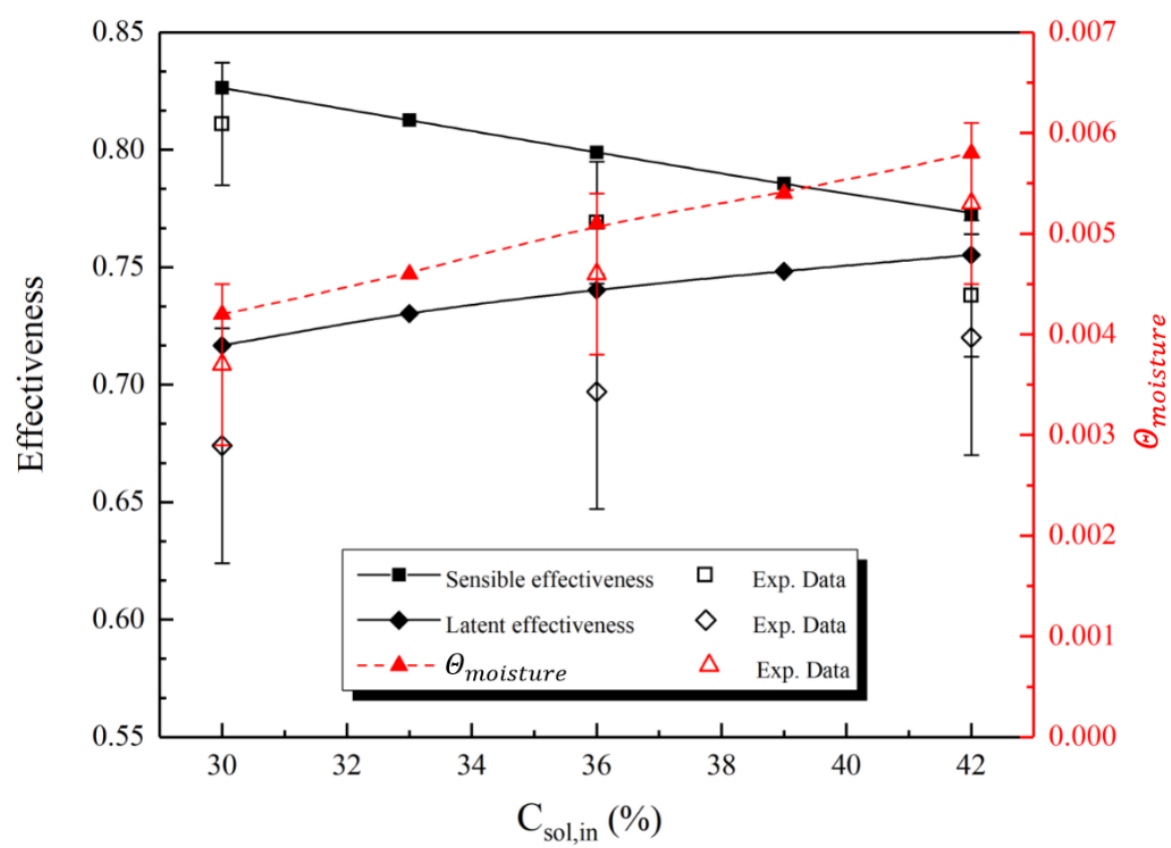

Fig. 22. Variations of effectiveness and moisture flux rate against $C_{\text {sol,in }}$

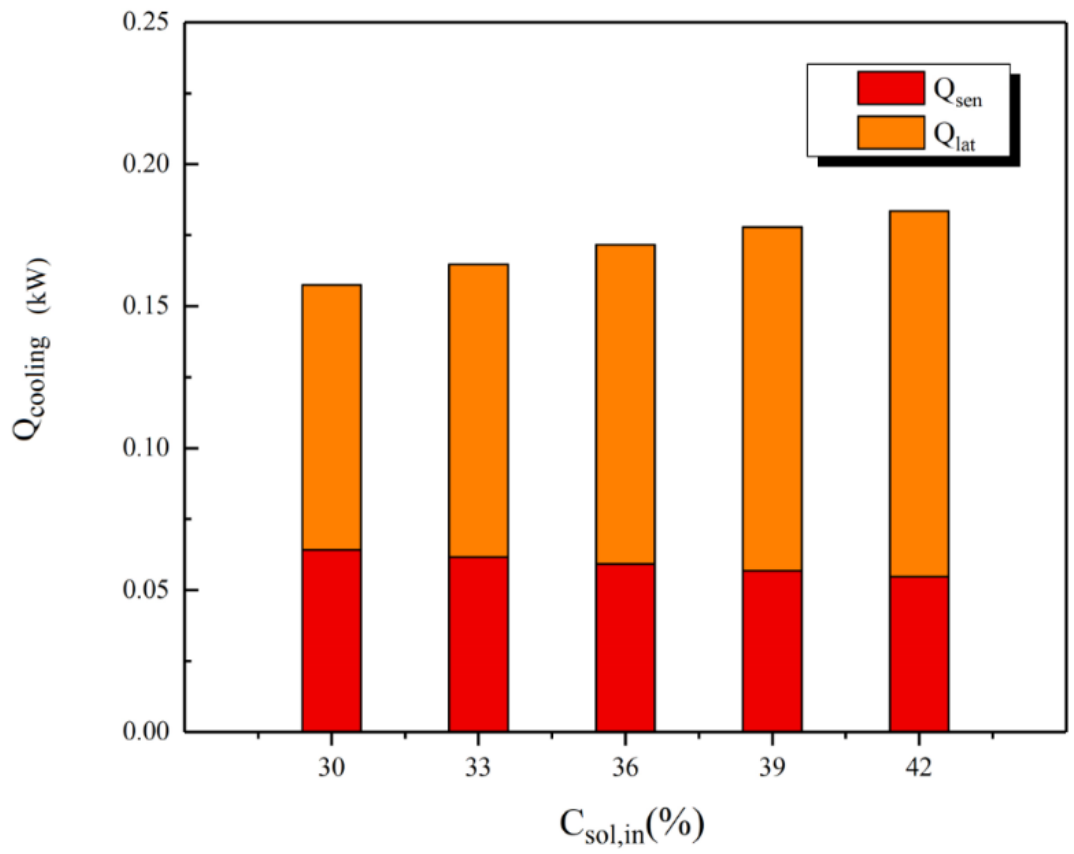

Fig. 23. Total cooling capacity $Q_{\text {cooling }}$ variation against $C_{\text {sol,in }}$ 


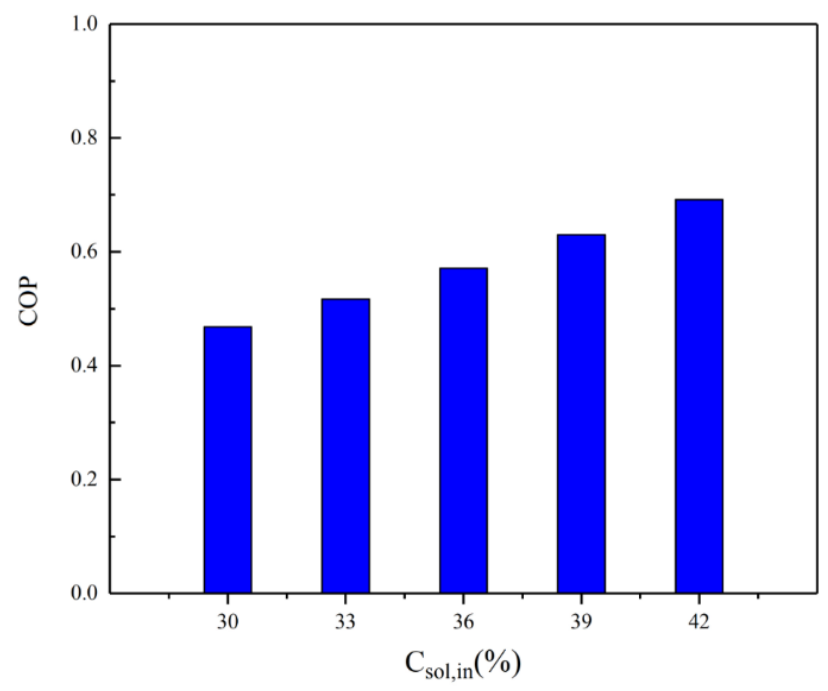

Fig. 24. $C O P$ variations against $C_{\text {sol,in }}$

As shown in Fig. 22, increasing the dehumidifier inlet solution concentration from $30 \%$ to $42 \%$ would improve the latent effectiveness from 0.717 to 0.755 and decrease the system sensible effectiveness from 0.826 to 0.773 . The solution surface vapour pressure decreases with its concentration, as the result the solution absorption capacity and the latent effectiveness are enhanced. Similarly, the moisture flux rate $\Theta_{\text {moisture }}$ is improved as well, it rises from 0.0042 to 0.0058 as $C_{\text {sol, in }}$ increases from $30 \%$ to $42 \%$. At the same time, the system sensible effectiveness decreases as the increased dehumidification capacity has negative influence on the sensible effectiveness for more latent heat being released to the solution side. With regard to the cooling energy capacity, it can be seen in Fig. 23 that the sensible cooling capacity slightly decreases with $C_{\text {sol,in }}$, while the latent cooling capacity increases. Since only the solution inlet property is changed, both the solution and air mass flow rates remain constant, thus the variations of the sensible and latent cooling capacities have the direct relationships with the sensible and latent effectiveness. So the sensible cooling capacity reduces from 0.064 $\mathrm{kW}$ to $0.055 \mathrm{~kW}$, and the latent cooling capacity increases from $0.093 \mathrm{~kW}$ to $0.129 \mathrm{~kW}$. As the result, the total cooling capacity $Q_{\text {cooling }}$ is improved slightly from $0.158 \mathrm{~kW}$ to $0.184 \mathrm{~kW}$. As displayed in Fig. 24, $C_{\text {sol,in }}$ has considerable impact on the system COP. Although the total cooling capacity is improved, the change is almost negligible. Another important fact is that the regeneration energy $Q_{r e g}$ reduces with $C_{\text {sol,in }}$. For example, when $C_{\text {sol,in }}$ increases from $30 \%$ to $42 \%, Q_{\text {reg }}$ decreases by $21.36 \%$ from $0.337 \mathrm{~kW}$ to $0.265 \mathrm{~kW}$. This is caused by the reduction of the solution temperature difference between the inlet and outlet of the regenerator after rising the solution inlet concentration.

In real application, low solution temperature is not suitable to reduce energy consumption, thus increasing the solution inlet concentration in the dehumidifier is more applicable and would be a good way to improve the system dehumidification and energy performance. It should be 
mentioned that the high concentrated solution may induce the solution crystallization, this would bring more problems such as mal-distribution, membrane fouling and high pumping pressure. Thus the operating condition should be assessed to avoid crystallization when using high concentration solution.

\subsection{Feasible solutions in practical applications}

Based on the main results as given in section 6.2 and 6.3, it can be summarized that $N T U_{d e}$ and $m^{*}$ have the most considerable impact on the system performance, while $N T U_{r e}$ and $C_{\text {sol,in }}$ have relatively weak influences. It is preferable to keep $N T U_{r e}$ below its critical value of 6 . In practical applications $N T U_{r e}$ is adjusted by changing the heat and mass transfer area (contact area) of the dehumidifier, but increasing the contact area with exceeding $N T U_{d e, c r i t}$ would not enhance the system performance. By contrast, adjusting the regenerator contact area would not affect the system performance significantly.

Once the air mass flow rate has been determined, then $m^{*}$ is changed by adjusting the solution mass flow rate. System effectiveness, moisture removal flux rate and cooling capacity increase with $m^{*}$ initially, but then decrease. As the result, when adjusting the solution mass flow rate, it is preferable to keep $m^{*}$ at or below its critical value. It also should be noticed that the selection of solution mass flow rate should be based on $N T U$ as the corresponding $m^{*}$ for the highest value is different.

Moreover, with regard to the desiccant solution, increasing the solution concentration for the dehumidifier is more applicable to improve the system dehumidification and energy performance compared with reducing the solution temperature.

Last but not least, due to the fact that system latent cooling capacity is dramatically higher than sensible cooling capacity, the process air after the dehumidifier should be further cooled before being supplied to air-conditioned spaces.

\section{Conclusions}

A complete membrane-based liquid desiccant dehumidification system, that mainly contains a dehumidifier, a regenerator, a cold and a hot water supply units, is investigated through dehumidification performance evaluation and energy assessment. Heat and mass transfer in the dehumidifier and regenerator are studied by numerical simulation and experimental tests. The dehumidification performance is assessed by the system sensible and latent effectiveness $\varepsilon_{\text {sen,sys }}, \varepsilon_{\text {lat,sys }}$ and moisture flux rate $\Theta_{\text {moisture }}$, while its energy performance is evaluated by the total cooling capacity $Q_{\text {cooling }}$ and coefficient of performance $C O P$. The effects of main parameters are clarified, which include the dehumidifier side $N T U_{d e}$, regenerator side $N T U_{r e}$, mass flow rate ratio $m^{*}$ and solution inlet concentration in the dehumidifier $C_{\text {sol,in }}$. The main findings are summarised as follows: 
- The boundary conditions of the membrane surfaces in the dehumidifier and regenerator are neither uniform temperature nor uniform humidity ratio, and they vary along the diagonal lines of the membranes.

- $\quad N T U_{d e}$ and $m^{*}$ are directly related to the solution and air mass flow rates in the dehumidifier. $N T U_{d e}$ and $m^{*}$ have the most considerable impact on the system performance, while $N T U_{r e}$ and $C_{s o l, \text { in }}$ have relatively weak influences.

- The system sensible and latent effectiveness can be improved by up to 0.62 and 0.65 respectively by increasing $N T U_{d e}$ from 1 to 6 , however their increasing gradients hardly change when $N T U_{d e}$ exceeds its critical value $N T U_{d e, c r i t}$ of 6 in this study.

- Although the system effectiveness increase with $N T U_{d e}$, the total amount of moisture being absorbed, $Q_{\text {cooling }}$ and $C O P$ decrease with $N T U_{d e}$. Thus there is no meaning to increase $N T U_{d e}$ over $N T U_{d e, c r i t}$ for the performance improvement.

- The latent cooling capacity $Q_{\text {lat }}$ is significantly (up to 3.92 times under $N T U_{d e}=1$ and $N T U_{r e}=4$ ) higher than the sensible cooling capacity $Q_{s e n}$, so the process air should be further cooled after being dehumidified.

- The system effectiveness, moisture removal flux rate and cooling capacity increase with $m^{*}$ initially, but then decrease. The corresponding $m^{*}$ for the highest values are different for various $N T U$ values (such as 1.5 for $N T U=4,2$ for $N T U=6$ and 3 for $N T U=6$ respectively). It is preferable to keep $m^{*}$ at or below its critical value as further increasing $m^{*}$ would reduce the system COP.

- Increasing the solution inlet concentration for the dehumidifier is more applicable to improve the system dehumidification and energy performance compared with reducing the solution temperature. However the problem of crystallization should be avoided when applying high concentration solution.

- For the future research, the internally cooled system should be designed for the dehumidifier as the latent heat generated in the dehumidifier has negative effect on the system performance. Furthermore, the diluted solution is regenerated by an electrical boiler in this study, so the low-grade energy sources such as solar collector or waste heat could be integrated to the dehumidification system to make the complete system more sustainable. 


\section{References}

[1] H. Zhong, J. Wang, H. Jia, Y. Mu, S. Lv, Vector field-based support vector regression for building energy consumption prediction, Applied Energy, 242 (2019) 403-414.

[2] B. Becerik-Gerber, M. Siddiqui, I. Brilakis, O. El-Anwar, N. El-Gohary, T. Mahfouz, G. Jog, S. Li, A. Kandil, Civil Engineering Grand Challenges: Opportunities for Data Sensing, Information Analysis, and Knowledge Discovery, 2013.

[3] A.S. Ahmad, M.Y. Hassan, M.P. Abdullah, H.A. Rahman, F. Hussin, H. Abdullah, R. Saidur, A review on applications of ANN and SVM for building electrical energy consumption forecasting, Renewable and Sustainable Energy Reviews, 33 (2014) 102-109.

[4] D.K. Lim, B.H. Ahn, J.H. Jeong, Method to control an air conditioner by directly measuring the relative humidity of indoor air to improve the comfort and energy efficiency, Applied Energy, 215 (2018) 290-299.

[5] Y. Huang, J.-l. Niu, Optimal building envelope design based on simulated performance: History, current status and new potentials, Energy and Buildings, 117 (2016) 387-398.

[6] G.Y. Yun, Influences of perceived control on thermal comfort and energy use in buildings, Energy and Buildings, 158 (2018) 822-830.

[7] Y. Huang, A. Khajepour, F. Bagheri, M. Bahrami, Optimal energy-efficient predictive controllers in automotive air-conditioning/refrigeration systems, Applied Energy, 184 (2016) 605-618.

[8] X.-W. Li, X.-S. Zhang, F. Wang, X. Zhao, Z. Zhang, Research on ration selection of mixed absorbent solution for membrane air-conditioning system, Energy Conversion and Management, 89 (2015) 111-119.

[9] A. Zendehboudi, Implementation of GA-LSSVM modelling approach for estimating the performance of solid desiccant wheels, Energy Conversion and Management, 127 (2016) 245255.

[10] M. Gadalla, M. Saghafifar, Performance assessment and transient optimization of air precooling in multi-stage solid desiccant air conditioning systems, Energy Conversion and Management, 119 (2016) 187-202.

[11] M.R. Islam, S.W.L. Alan, K.J. Chua, Studying the heat and mass transfer process of liquid desiccant for dehumidification and cooling, Applied Energy, 221 (2018) 334-347.

[12] M.M. Rafique, P. Gandhidasan, H.M.S. Bahaidarah, Liquid desiccant materials and dehumidifiers - A review, Renewable and Sustainable Energy Reviews, 56 (2016) 179-195.

[13] X.H. Liu, Y. Jiang, X.Q. Yi, Effect of regeneration mode on the performance of liquid desiccant packed bed regenerator, Renewable Energy, 34 (2009) 209-216.

[14] L.-Z. Zhang, Progress on heat and moisture recovery with membranes: From fundamentals to engineering applications, Energy Conversion and Management, 63 (2012) 173-195. 
[15] D. Ghadiri Moghaddam, R.W. Besant, C.J. Simonson, Solution-side effectiveness for a liquid-to-air membrane energy exchanger used as a dehumidifier/regenerator, Applied Energy, 113 (2014) 872-882.

[16] H. Bai, J. Zhu, Z. Chen, J. Chu, Parametric analysis of a cross-flow membrane-based parallel-plate liquid desiccant dehumidification system: Numerical and experimental data, Energy and Buildings, 158 (2018) 494-508.

[17] H. Bai, J. Zhu, Z. Chen, L. Ma, R. Wang, T. Li, Performance testing of a cross-flow membrane-based liquid desiccant dehumidification system, Applied Thermal Engineering, 119 (2017) 119-131.

[18] B. Su, W. Han, H. Jin, An innovative solar-powered absorption refrigeration system combined with liquid desiccant dehumidification for cooling and water, Energy Conversion and Management, 153 (2017) 515-525.

[19] S.-M. Huang, L.-Z. Zhang, K. Tang, L.-X. Pei, Fluid flow and heat mass transfer in membrane parallel-plates channels used for liquid desiccant air dehumidification, International Journal of Heat and Mass Transfer, 55 (2012) 2571-2580.

[20] S.-M. Huang, L.-Z. Zhang, M. Yang, Conjugate heat and mass transfer in membrane parallel-plates ducts for liquid desiccant air dehumidification: Effects of the developing entrances, Journal of Membrane Science, 437 (2013) 82-89.

[21] R. Qi, D. Li, L.-Z. Zhang, Performance investigation on polymeric electrolyte membranebased electrochemical air dehumidification system, Applied Energy, 208 (2017) 1174-1183.

[22] J. Lin, S.-M. Huang, R. Wang, K.J. Chua, Thermodynamic analysis of a hybrid membrane liquid desiccant dehumidification and dew point evaporative cooling system, Energy Conversion and Management, 156 (2018) 440-458.

[23] A.R. Vijay Babu, P. Manoj Kumar, G. Srinivasa Rao, Parametric study of the proton exchange membrane fuel cell for investigation of enhanced performance used in fuel cell vehicles, Alexandria Engineering Journal, 57 (2018) 3953-3958.

[24] A.R. Vijay Babu, P. Manoj Kumar, G. Srinivasa Rao, Effect of Design and Operating Parameters on the Performance of Planar and Ducted Cathode Structures of an Air-Breathing PEM Fuel Cell, Arabian Journal for Science and Engineering, 41 (2016) 3415-3423.

[25] H. Bai, J. Zhu, Z. Chen, J. Chu, Y. Liu, Performance evaluation of a membrane-based flatplate heat and mass exchanger used for liquid desiccant regeneration, Applied Thermal Engineering, 139 (2018) 569-584.

[26] H. Jafarian, H. Sayyaadi, F. Torabi, Numerical modeling and comparative study of different membrane-based liquid desiccant dehumidifiers, Energy Conversion and Management, 184 (2019) 735-747. 
[27] S.-M. Huang, J.-C. Luo, M. Yang, W.-Z. Yuan, Y. Hong, W.-B. Ye, Hexagonal parallelplate air/liquid membrane contactor (HPMC) for liquid desiccant air dehumidification, International Journal of Refrigeration, 100 (2019) 392-403.

[28] K. Mahmud, G.I. Mahmood, C.J. Simonson, R.W. Besant, Performance testing of a counter-cross-flow run-around membrane energy exchanger (RAMEE) system for HVAC applications, Energy and Buildings, 42 (2010) 1139-1147.

[29] H.B. Hemingson, C.J. Simonson, R.W. Besant, Steady-state performance of a run-around membrane energy exchanger (RAMEE) for a range of outdoor air conditions, International Journal of Heat and Mass Transfer, 54 (2011) 1814-1824.

[30] G. Ge, D. Ghadiri Moghaddam, R. Namvar, C.J. Simonson, R.W. Besant, Analytical model based performance evaluation, sizing and coupling flow optimization of liquid desiccant run-around membrane energy exchanger systems, Energy and Buildings, 62 (2013) 248-257.

[31] M. Seyed-Ahmadi, B. Erb, C.J. Simonson, R.W. Besant, Transient behavior of run-around heat and moisture exchanger system. Part I: Model formulation and verification, International Journal of Heat and Mass Transfer, 52 (2009) 6000-6011.

[32] M. Seyed-Ahmadi, B. Erb, C.J. Simonson, R.W. Besant, Transient behavior of run-around heat and moisture exchanger system. Part II: Sensitivity studies for a range of initial conditions, International Journal of Heat and Mass Transfer, 52 (2009) 6012-6020.

[33] M. Rasouli, S. Akbari, C.J. Simonson, R.W. Besant, Energetic, economic and environmental analysis of a health-care facility HVAC system equipped with a run-around membrane energy exchanger, Energy and Buildings, 69 (2014) 112-121.

[34] D. Ghadiri Moghaddam, A. Oghabi, G. Ge, R.W. Besant, C.J. Simonson, Numerical model of a small-scale liquid-to-air membrane energy exchanger: Parametric study of membrane resistance and air side convective heat transfer coefficient, Applied Thermal Engineering, 61 (2013) 245-258.

[35] D.P.D. Frank P. Incropera, Theodore L. Bergman, Adrienne S. Lavine Principles of Heat and Mass Transfer seventh edition ed., Jogn Wiley \& Sons, Inc2012

[36] Y.H. Zurigat, M.K. Abu-Arabi, S.A. Abdul-Wahab, Air dehumidification by triethylene glycol desiccant in a packed column, Energy Conversion and Management, 45 (2004) 141-155. 


\section{Appendix A}

The discretised governing equations using finite difference method are given as:

$$
\begin{aligned}
& T_{\text {sol }(i+1, j)}{ }^{*}-T_{\text {sol }(i, j)}{ }^{*}-d y^{*} N T U_{m} h^{*} \Upsilon^{*}\left[W_{\text {air }(i+1, j)}{ }^{*}-W_{\text {sol,mem }(i+1, j)}{ }^{*}\right]-d y^{*} N T U \Upsilon^{*}\left[T_{\text {air }(i+1, j)}{ }^{*}-\right. \\
& \left.T_{\text {sol }(i+1, j)}{ }^{*}\right]=0 \\
& \omega_{\text {sol }(i+1, j)}-\omega_{\text {sol }(i, j)}-d y^{*} m^{*} W_{0} N T U_{m}\left[1+\omega_{\text {sol }(i+1, j)}\right]\left[W_{\text {air }(i+1, j)}{ }^{*}-W_{\text {sol,mem }(i+1, j)}{ }^{*}\right]=0 \\
& T_{\text {air }(i, j+1)}{ }^{*}-T_{\text {air }(i, j)}{ }^{*}+d x^{*} N T U\left[T_{\text {air }(i, j+1)}{ }^{*}-W_{\text {sol }(i, j+1)}{ }^{*}=0\right. \\
& W_{\text {air }(i, j+1)}{ }^{*}-W_{\text {air }(i, j)}{ }^{*}+d x^{*} N T U_{m}\left[W_{\text {air }(i, j+1)}{ }^{*}-W_{\text {sol,mem }(i, j+1)}{ }^{*}\right]=0 \\
& T_{\text {sol }(i+1, j)}^{*}-T_{\text {sol }(i, j)}^{*}+d y^{*} N T U_{m} h^{*} \Upsilon^{*}\left[W_{\text {sol,mem }(i+1, j)}^{*}-W_{\text {air }(i+1, j)}^{*}\right]+d y^{*} N T U Y^{*}\left[T_{\text {sol }(i+1, j)}^{*}-\right. \\
& \left.T_{\text {air }(i+1, j)}^{*}\right]=0 \\
& \omega_{\text {sol }(i+1, j)}-\omega_{\text {sol }(i, j)}+d y^{*} m^{*} W_{0} N T U_{m}\left[1+\omega_{\text {sol }(i+1, j)}\right]\left[W_{\text {sol,mem }(i+1, j)}^{*}-W_{\text {air }(i+1, j)}^{*}\right]=0 \\
& T_{\text {air }(i, j+1)}^{*}-T_{\text {air }(i, j)}^{*}-d x^{*} N T U\left[T_{\text {sol }(i, j+1)}^{*}-T_{\text {air }(i, j+1)}^{*}=0\right. \\
& W_{\text {air }(i, j+1)}^{*}-W_{\text {air }(i, j)}^{*}-d x^{*} N T U_{m}\left[W_{\text {sol,mem }(i, j+1)}^{*}-W_{\text {air }(i, j+1)}^{*}\right]=0
\end{aligned}
$$

where $m$ and $n$ are numbers of girds in $\mathrm{x}$ and $\mathrm{y}$ directions respectively. 


\section{Nomenclature}

\begin{tabular}{ll}
$A$ & membrane surface area $\left(\mathrm{m}^{2}\right)$ \\
$c_{p}$ & specific heat capacity $(\mathrm{J} / \mathrm{kgK})$ \\
$C$ & concentration $(\%)$ \\
$C O P$ & coefficient of performance \\
$C_{r}{ }^{*}$ & thermal capacity ratio \\
$d$ & width of the rectangular channel $(\mathrm{m})$ \\
$D$ & diffusivity $\left(\mathrm{m}^{2} / \mathrm{s}\right)$ \\
$Q$ & Power $(\mathrm{kW})$ \\
$h$ & convective heat transfer coefficient $\left(\mathrm{W} / \mathrm{m}^{2} \mathrm{~K}\right)$ \\
$h_{f g}$ & condensation heat of water $(\mathrm{J} / \mathrm{kg})$ \\
$h^{*}$ & operating factor \\
$H$ & height of the dehumidifier unit $(\mathrm{m})$ \\
$k$ & thermal conductivity $(\mathrm{W} / \mathrm{m} \mathrm{K})$ \\
$L$ & length of the dehumidifier unit $(\mathrm{m})$ \\
$m^{*}$ & solution to air mass flow rate ratio \\
$\dot{m}$ & mass flow rate $(\mathrm{kg} / \mathrm{s})$ \\
$N T U$ & number of heat transfer units \\
$N T U_{m}$ & number of mass transfer units \\
$R e$ & Reynolds number \\
$T$ & temperature $\left({ }^{\circ} \mathrm{C}\right)$ \\
$U$ & overall heat transfer coefficient $\left(\mathrm{W} / \mathrm{m}^{2} \mathrm{~K}\right)$ \\
$U_{m}$ & overall mass transfer coefficient $\left(\mathrm{kg} / \mathrm{m}^{2} \mathrm{~s}\right)$ \\
$X$ & volumetric flow rate $(\mathrm{l} / \mathrm{min})$ \\
& humidity ratio $(\mathrm{kg} / \mathrm{kg}$ dry air $)$ \\
\hline &
\end{tabular}

\section{Greeks}

$\varepsilon$

effectiveness

$\delta \quad$ thickness of membrane (m)

$\eta \quad$ efficiency

$\Theta \quad$ moisture flux rate

$\rho \quad$ density $\left(\mathrm{kg} / \mathrm{m}^{3}\right)$ 


\section{Superscripts}

dimensionless

\section{Subscripts}

$\begin{array}{ll}\text { air } & \text { air flow } \\ \text { crit } & \text { critical value } \\ d & \text { duct } \\ \text { de } & \text { dehumidifier } \\ \text { desi } & \text { desiccant } \\ \text { exp } & \text { experimental } \\ \text { fan } & \text { fan } \\ \text { in } & \text { inlet } \\ \text { lat } & \text { latent } \\ \text { m } & \text { mass transfer } \\ \text { mem } & \text { membrane } \\ \text { moisture } & \text { moisture } \\ \text { num } & \text { numerical } \\ \text { out } & \text { outlet } \\ \text { pump } & \text { pump } \\ \text { sen } & \text { sensible } \\ \text { sol } & \text { solution flow } \\ \text { sys } & \text { system } \\ \text { tol } & \text { total }\end{array}$

